\title{
Platinum Clusters on Vacancy-Type Defects of Nanometer-Sized Graphene Patches
}

\author{
Takashi Yumura ${ }^{1, *}$, Tatsuya Awano ${ }^{2}$, Hisayoshi Kobayashi ${ }^{2}$ and Tokio Yamabe ${ }^{2}$ \\ 1 Department of Chemistry and Materials Technology, Kyoto Institute of Technology, Matsugasaki, \\ Sakyo-ku, Kyoto 606-8585, Japan \\ 2 Nagasaki Institute of Applied Science, 536 Aba-machi, Nagasaki 851-0193, Japan \\ * Author to whom correspondence should be addressed; E-Mail: yumura@chem.kit.ac.jp; \\ Tel.: +81-75-724-7571; Fax: +81-75-724-7580.
}

Received: 8 May 2012; in revised form: 11 June 2012 / Accepted: 19 June 2012 /

Published: 2 July 2012

\begin{abstract}
Density functional theory calculations found that spin density distributions of platinum clusters adsorbed on nanometer-size defective graphene patches with zigzag edges deviate strongly from those in the corresponding bare clusters, due to strong Pt-C interactions. In contrast, platinum clusters on the pristine patch have spin density distributions similar to the bare cases. The different spin density distributions come from whether underlying carbon atoms have radical characters or not. In the pristine patch, center carbon atoms do not have spin densities, and they cannot influence radical characters of the absorbed cluster. In contrast, radical characters appear on the defective sites, and thus spin density distributions of the adsorbed clusters are modulated by the Pt-C interactions. Consequently, characters of platinum clusters adsorbed on the $\mathrm{sp}^{2}$ surface can be changed by introducing vacancy-type defects.
\end{abstract}

Keywords: density functional theory; graphene; cluster; catalyst; spin state

\section{Introduction}

Graphitic carbon materials serve as a support material [1] for anode catalysts such as platinum clusters in proton exchange membrane (PEM) fuel cells [2-9]. The supported Pt clusters catalyze the activation of hydrogen molecules to form protons and electrons on the anode of fuel cells. Consequently, the size of Pt clusters is a crucial parameter in determining their catalytic activity. 
Actually, clusters of less than $3 \mathrm{~nm}$ are more effective for catalyzing the $\mathrm{H}_{2}$ dissociation [9]. During the catalytic reactions, adjacent clusters tend to coalescence, forming larger clusters. Accordingly, their catalytic activity decreases as the reaction proceeds. To retain the catalytic activity of supported Pt catalysts, a plausible approach is to strengthen interactions between Pt clusters and underlying carbon $\mathrm{sp}^{2}$ surface.

To come up with a strategy for constructing carbon supports suitable for Pt catalysts, computational simulations are becoming a powerful tool [9-31]. Several computational studies suggest that disrupting the $\mathrm{sp}^{2}$ surface by introducing defects (vacancy-type and Stone-Wales type) [9,18,21,25,26,29-31], dopants (nitrogen or boron impurities) [14-16], and mechanical strain [25] can enhance the interactions with Pt clusters. With respect to the formation of the vacancy-type defects, recent high-resolution transmission electron microscopy (TEM) studies [32-35] show that electron irradiation of graphene creates vacancy-type defects by removing a few carbon atoms from the surface. After these events, unsaturated carbon atoms are generated. Some of the unsaturated atoms make a covalent bond with an adjacent atom to form a five-membered ring, whereas the others remain two-coordinated. These carbon atoms, which cannot be seen in pristine graphene, are more chemically reactive, and thus they serve as sites for strong adsorption of Pt clusters. Reactive carbon atoms can be also found on edges of zigzag-nanoribbons and zigzag-graphene patches, because their frontier orbital coefficients are located on edge carbon atoms [36-42]. Thus, one can utilize such reactive edge atoms to trap well Pt clusters [22,27]. Previously, we investigated by means of density functional theory (DFT) calculations how a Pt cluster is bound to the nanometer-size rhombic $\mathrm{sp}^{2}$ patch with zigzag-edges $\left(\mathrm{C}_{96} \mathrm{H}_{26}\right)$ (Figure 1) [22]. Such H-terminated $\mathrm{sp}^{2}$ patches are contained in activated carbons as condensed-aromatic-ring fractions [43]. The DFT calculations found that a $\mathrm{Pt}_{6}$ cluster preferentially binds into edge atoms of $\mathrm{C}_{96} \mathrm{H}_{26}$ rather than into center atoms. In fact, the $\mathrm{Pt}_{6}$ additions to edge atoms were about $50 \mathrm{kcal} / \mathrm{mol}$ more stable than those to center atoms [22].

Figure 1. Optimized structure for $\mathrm{C}_{96} \mathrm{H}_{26}$ graphene patch.

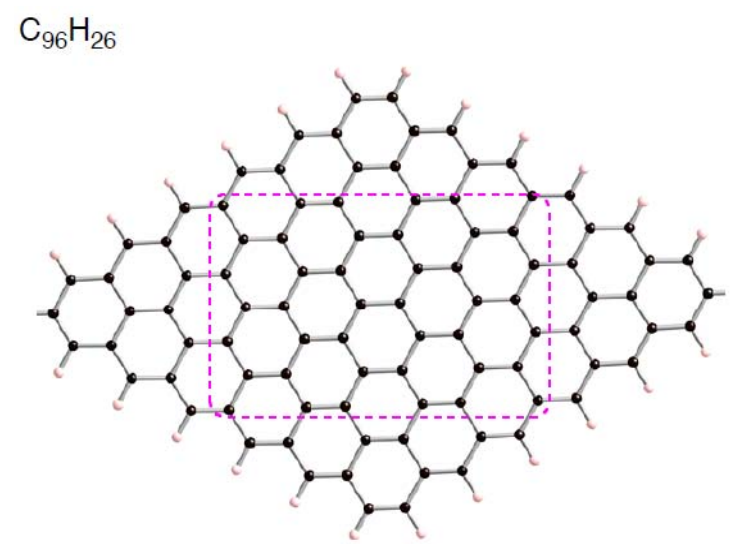

Another interesting feature of nanometer-size graphenes is that they have radical character in the ground state, depending on their shape and size [44-51]. Thus, we assume that interactions between a Pt cluster and a radical $\mathrm{sp}^{2}$ patch can modulate the catalytic activity of the supported cluster due to the onset of unpaired electrons on Pt atoms. Based on the assumption, the current study will focus on whether spin states of $\mathrm{C}_{96} \mathrm{H}_{26}$ support have a power to influence the properties of the adsorbed 
Pt clusters. Furthermore, we are interested in how introduction of vacancy-type defects on the radical $\mathrm{C}_{96} \mathrm{H}_{26}$ support changes the electronic properties of the surface. These changes would have an impact on determining the properties of Pt clusters adsorbed on the $\mathrm{sp}^{2}$ support. To increase our understanding of the interactions between a radical $\mathrm{sp}^{2}$ support and a Pt cluster, we performed density functional theory (DFT) calculations. The main aim in the current DFT study is to clarify how different electronic properties of $\mathrm{C}_{96} \mathrm{H}_{26}$ support with or without vacancy-type defects influence the interactions with Pt clusters, and concomitantly the properties of the absorbed clusters.

\section{Results and Discussion}

\subsection{Platinum Clusters on $\mathrm{C}_{96} \mathrm{H}_{26}$ in the Triplet State}

To obtain a basic insight on how different spin states of $\mathrm{C}_{96} \mathrm{H}_{26}$ patch affect the interactions with Pt clusters, we investigated how $\mathrm{Pt}_{6}$ clusters bind into the $\mathrm{sp}^{2}$ surface. Following the previous study [22], two types of $\mathrm{Pt}_{6}$ cluster were considered, denoted by (i) and (ii) in Figure 2. The DFT calculations found that their triplet states are energetically stable relative to the corresponding singlet states. The stability of spin-polarized states in Pt clusters was also reported by other groups [52-54]. We obtained three optimized geometries for $\mathrm{Pt}_{6}(\mathrm{i})$ or $\mathrm{Pt}_{6}$ (ii) clusters adsorbed on $\mathrm{C}_{96} \mathrm{H}_{26}\left(\mathrm{Pt}_{6}-\mathrm{C}_{96} \mathrm{H}_{26}\right)$ in the singlet and triplet states. Within the three optimized geometries in Figure 3, one is that the $\mathrm{Pt}_{6}(\mathrm{i})$ cluster makes four Pt-C bonds with the $\mathrm{sp}^{2}$ surface, and the other two are distinguished by whether the number of $\mathrm{Pt}-\mathrm{C}$ bonds formed between the $\mathrm{Pt}_{6}$ (ii) cluster and the surface is 2 or 4 . In these geometries, optimized lengths of Pt-C bonds range from 2.288 to $2.334 \AA$.

Figure 2. Optimized structures for bare $\mathrm{Pt}_{6}$ cluster, and their spin density distributions. Isosurface $\alpha$ - and $\beta$-spins are given by pink and blue, respectively.

(i) $\mathrm{Pt}_{6}$ geometry

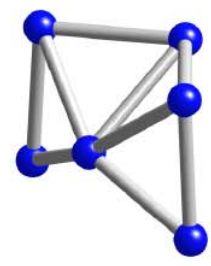

spin density distributions

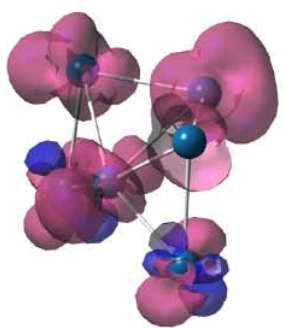

(ii) $\mathrm{Pt}_{6}$ geometry

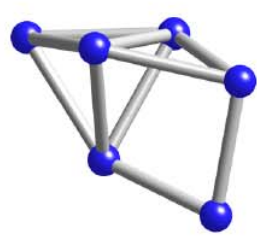

spin density distributions

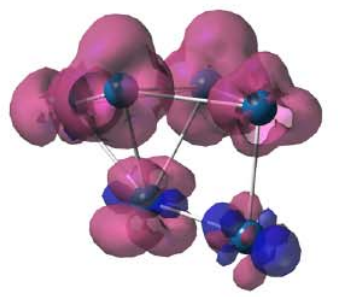

We estimated in Table 1 the energy difference between the triplet and singlet spin states in each configuration, $\Delta E_{\text {state }}\left(\mathrm{Pt}_{6}-\mathrm{C}_{96} \mathrm{H}_{26}\right)$, defined as $\left[E_{\text {total }}\right.$ (triplet state) $-E_{\text {total }}$ (singlet state) $]$ where $E_{\text {total }}$ (triplet state) or $E_{\text {total }}$ (singlet state) is the total energy in each state. As shown in Table 1, the three configurations have negative $\Delta E_{\text {state }}\left(\mathrm{Pt}_{6}-\mathrm{C}_{96} \mathrm{H}_{26}\right)$ values. These negative $\Delta E_{\text {state }}\left(\mathrm{Pt}_{6}-\mathrm{C}_{96} \mathrm{H}_{26}\right)$ values indicate that the triplet state of a $\mathrm{Pt}_{6}-\mathrm{C}_{96} \mathrm{H}_{26}$ configuration is energetically favorable relative to the singlet state, irrespective of the cluster shapes. Furthermore, we see from Table 1 more significant $\Delta E_{\text {state }}$ values in the $\mathrm{Pt}_{6}-\mathrm{C}_{96} \mathrm{H}_{26}$ configurations than those in the bare $\mathrm{Pt}_{6}$ clusters. Thus, the Pt-C interactions influence relative stability of the triplet to singlet states of the $\mathrm{Pt}_{6}$ clusters.

Spin density distributions in the triplet $\mathrm{Pt}_{6}-\mathrm{C}_{96} \mathrm{H}_{26}$ structures are also displayed in Figure 3, where isosurface $\alpha$ - and $\beta$-spins are given by pink and blue, respectively. As shown in Figure 3, the Pt-C 
interactions induce spin densities on $\mathrm{C}_{96} \mathrm{H}_{26}$, although the stable triplet state of pristine $\mathrm{C}_{96} \mathrm{H}_{26}$ has radical characters only on edge carbon atoms. Likewise, we see spin densities on the adsorbed Pt cluster in the configurations. Basically their spin density distributions are similar to those in the bare $\mathrm{Pt}_{6}$ clusters (Figure 2), but spin densities slightly decrease on $\mathrm{Pt}$ atoms that participates the Pt-C bond formation. The similarity between Pt clusters with and without the carbon support is understandable, because underlying carbon atoms do not have radical characters in pristine $\mathrm{C}_{96} \mathrm{H}_{26}$ in the stable triplet state, and thus they cannot perturb the spin density distributions of Pt clusters even though they interact substantially.

Figure 3. Spin density distributions of optimized $\mathrm{C}_{96} \mathrm{H}_{26}$ and $\mathrm{Pt}_{6}-\mathrm{C}_{96} \mathrm{H}_{26}$ configurations in the triplet state. Parts of the optimized geometries, corresponding to the region surrounded by pink hashed lines in Figure 1, are given. Isosurface $\alpha$ - and $\beta$-spins are given by pink and blue, respectively. Optimized bond lengths are in $\AA$.

$\mathrm{C}_{96} \mathrm{H}_{26}$

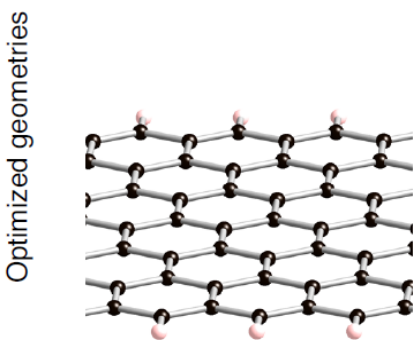

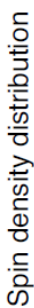

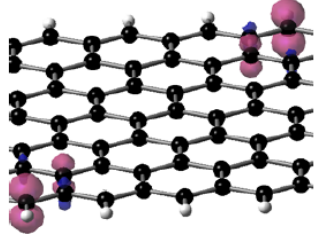

$\mathrm{Pt}_{6}(\mathrm{i})-\mathrm{C}_{96} \mathrm{H}_{26}$
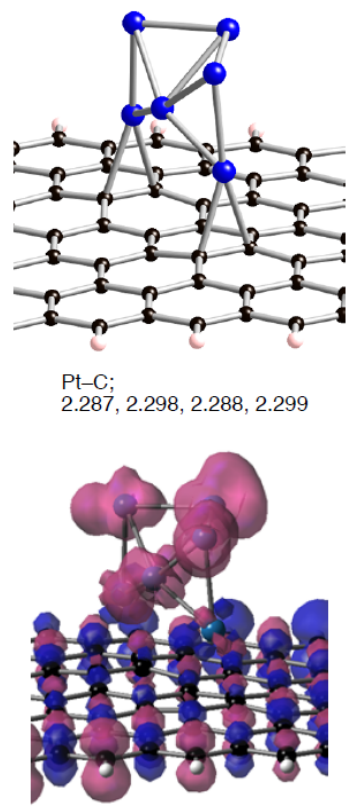

$\mathrm{Pt}_{6}(\mathrm{ii})-\mathrm{C}_{96} \mathrm{H}_{26}$ (1)
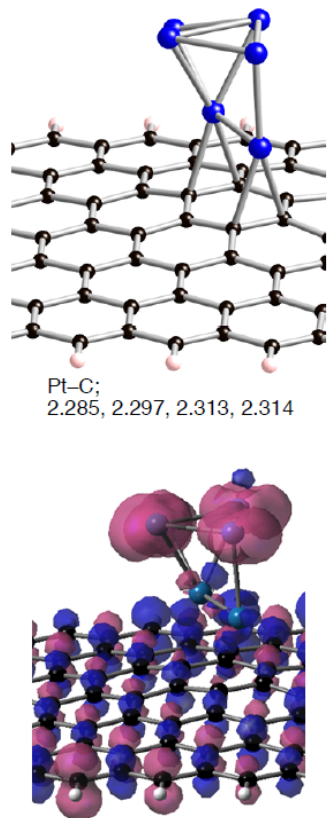

$\mathrm{Pt}_{6}(\mathrm{ii})-\mathrm{C}_{96} \mathrm{H}_{26}$ (2)

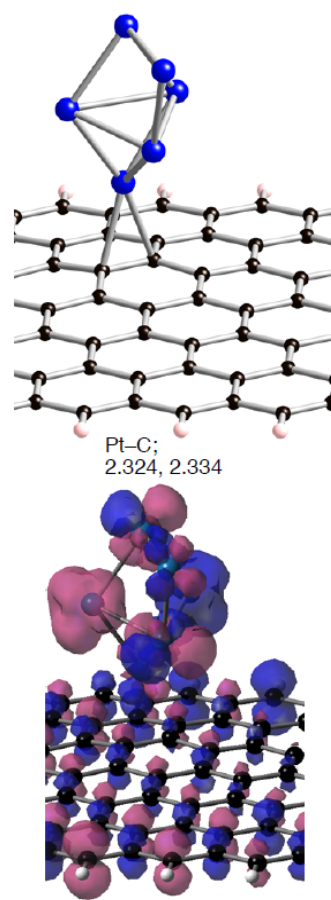

Table 1. Energy difference between the singlet and triplet states in $\mathrm{Pt}_{6}-\mathrm{C}_{96} \mathrm{H}_{26}\left(\Delta \mathrm{E}_{\text {state }} \text { in } \mathrm{kcal} / \mathrm{mol}\right)^{\mathrm{a}}$.

\begin{tabular}{cccc}
\hline & Pt $_{\mathbf{6}}$ (i) & Pt $_{\mathbf{6}}$ (ii)-(1) & $\mathbf{P t}_{\mathbf{6}}$ (ii)-(2) \\
\hline Bare clusters & -14.5 & -5.4 & -5.4 \\
Clusters on $\mathbf{C}_{\mathbf{9 6}} \mathbf{H}_{\mathbf{2 6}}$ & -31.4 & -23.6 & -22.1 \\
\hline
\end{tabular}

${ }^{\mathrm{a}} \Delta E_{\text {state }}\left(\mathrm{Pt}_{6}-\mathrm{C}_{96} \mathrm{H}_{26}\right)=E_{\text {total }}($ triplet state $)-E_{\text {total }}$ (singlet state). Negative $\Delta E_{\text {state }}$ values indicate that the triplet state of a $\mathrm{Pt}_{6}-\mathrm{C}_{96} \mathrm{H}_{26}$ configuration is energetically stable relative to the singlet state.

\subsection{Vacancy-Type Defects Formed by Removing Carbon Atoms from $\mathrm{C}_{96} \mathrm{H}_{26}$}

Prior to discussing Pt clusters adsorbed on the $\mathrm{sp}^{2}$ surface with vacancy-type defects, we look at how introduction of a vacancy-type defect on $\mathrm{C}_{96} \mathrm{H}_{26}$ changes its electronic structures. In this study, we considered the number $(n)$ of carbon atoms removed from $\mathrm{C}_{96} \mathrm{H}_{26}$, ranging from 1 to 3 . Removed 
carbon atoms are colored in Figure 4. First, we constructed mono-, di-, and tri-vacancy defects by removing the green atom, the green and blue atoms, and the three colored atoms, respectively. The vacancy-type defects will be denoted by $\mathrm{C}_{96-n} \mathrm{H}_{26}$. Using the initial geometries, we obtained optimized structures for the vacancy-type defects in the triple and singlet states. Then, the energy difference between the two spin states was evaluated in each vacancy-type defect, given as $\Delta E_{\text {state }}\left(\mathrm{C}_{96-n} \mathrm{H}_{26}\right)$ in Table 2. We can see from Table 2 negative $\Delta E_{\text {state }}\left(\mathrm{C}_{96-n} \mathrm{H}_{26}\right)$ values irrespective of the number of carbon atoms removed from $\mathrm{C}_{96} \mathrm{H}_{26}$. The negative $\Delta E_{\text {state }}\left(\mathrm{C}_{96-n} \mathrm{H}_{26}\right)$ values indicate that each $\mathrm{C}_{96-n} \mathrm{H}_{26}$ has energetically stable triplet state.

Figure 4. Vacancy type defects $\left(\mathrm{C}_{96-n} \mathrm{H}_{26}\right)$, constructed by removing a few carbon atoms from $\mathrm{C}_{96} \mathrm{H}_{26}$ where $n$ ranges from 1 to 3 . Parts of the optimized geometries, corresponding to the region surrounded by pink hashed lines in Figure 1, are given. Optimized bond lengths are given in $\AA$. Their spin density distributions in the triplet state are also given. Isosurface $\alpha$ - and $\beta$-spins are given by pink and blue, respectively.

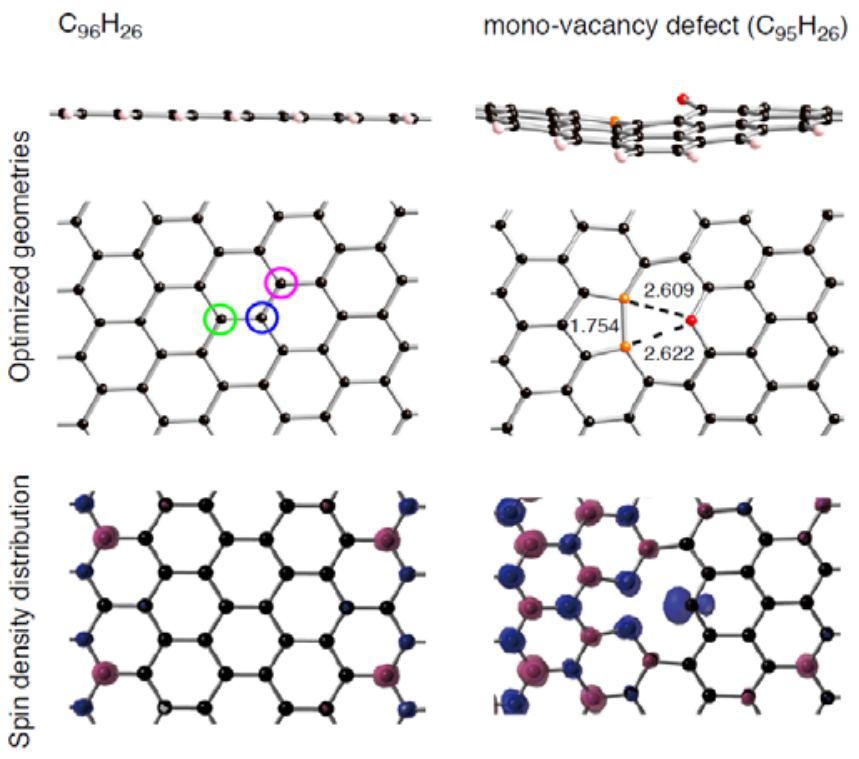

di-vacancy defect $\left(\mathrm{C}_{94} \mathrm{H}_{26}\right)$
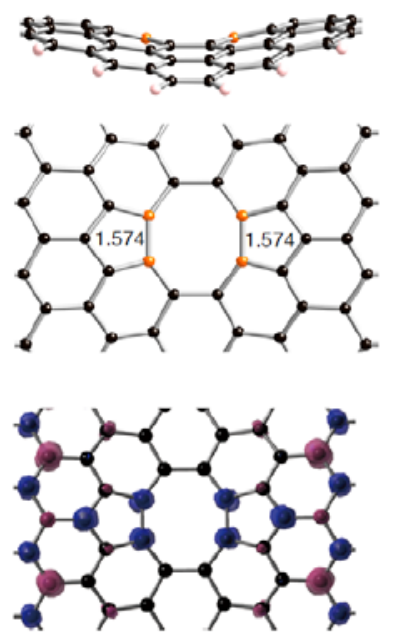

tri-vacancy defect $\left(\mathrm{C}_{93} \mathrm{H}_{26}\right)$
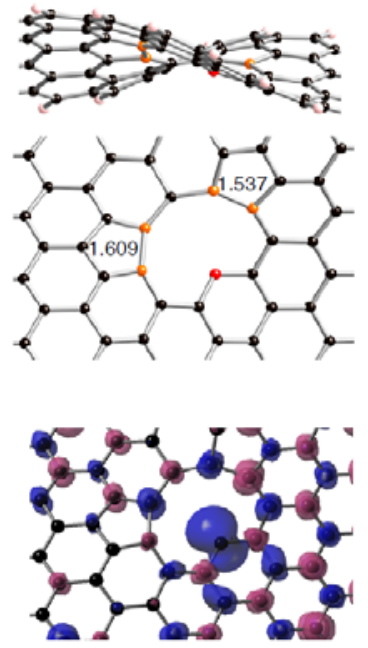

Table 2. Energy difference between the singlet and triplet states in $\mathrm{C}_{96-n} \mathrm{H}_{26}\left(\Delta \mathrm{E}_{\text {state }} \text { in } \mathrm{kcal} / \mathrm{mol}\right)^{\mathrm{a}}$.

\begin{tabular}{ccccc}
\hline & \multicolumn{4}{c}{$\boldsymbol{N}$} \\
\cline { 2 - 5 } & 0 & 1 & 2 & 3 \\
\hline$\Delta \boldsymbol{E}_{\text {state }}$ & -12.8 & -14.0 & -14.8 & -31.4
\end{tabular}

${ }^{\text {a }} \Delta E_{\text {state }}\left(\mathrm{C}_{96-n} \mathrm{H}_{26}\right)=E_{\text {total }}($ triplet state $)-E_{\text {total }}($ singlet state $)$. Negative $\Delta E_{\text {state }}$ values indicate that the triplet state of a $\mathrm{C}_{96-n} \mathrm{H}_{26}$ configuration is energetically stable relative to the singlet state.

Figure 4 also displays their optimized structures in the triplet state as well as corresponding spin density distributions. As shown in Figure 4, all optimized structures for the vacancy-type defects have some five-membered rings formed by connecting two orange atoms. There is one five-member ring in the mono-vacancy defect $\left(\mathrm{C}_{95} \mathrm{H}_{26}\right)$, while there are two five-member rings in the other vacancy-defects $\left(\mathrm{C}_{94} \mathrm{H}_{26}\right.$ and $\left.\mathrm{C}_{93} \mathrm{H}_{26}\right)$. Besides, removing odd-numbered carbon atoms from $\mathrm{C}_{96} \mathrm{H}_{26}$ generates one coordinatively unsaturated carbon atom, given by red in Figure 4. In fact, they are bound to only two neighboring atoms. The presence of vacancy-type defects perturbs significantly spin density 
distributions of pristine $\mathrm{C}_{96} \mathrm{H}_{26}$. As displayed in Figure 4, we can see radical carbon atoms around defective sites. In particular, significant spin densities were found in the tri-vacancy defect site. More interestingly, we found that the structural features of the defects have a correlation with how spin densities are distributed. On the unsaturated (red) atoms in the mono- and tri-vacancy-defects, spin densities are distributed on the carbon plane, which come from non-bonding orbitals. In contrast, spin densities on the orange atoms, which are a part of five-membered rings, are found perpendicular to the plane. The onset of radical carbon atoms at the center of the patch differentiates the defective surfaces from the pristine in terms of the interactions with Pt clusters, as will be mentioned below.

\subsection{Platinum Clusters on Vacancy-Type Defects $\left(\mathrm{C}_{96} \mathrm{H}_{26}\right)$ Depending on Spin States}

\subsubsection{Singlet State}

Despite the preferences of the triplet state of $\mathrm{C}_{96-n} \mathrm{H}_{26}$ over the singlet state, let us first use the singlet state to increase our understanding of how a $\mathrm{Pt}_{k}$ cluster interacts with a defective site on the $\mathrm{sp}^{2}$ surface. Following the previous study on interactions between a $\mathrm{Pt}_{6}$ cluster and pristine $\mathrm{C}_{96} \mathrm{H}_{26}$, we have a special interest on how the presence of a vacancy-type defect of the patch affects the interactions with a $\mathrm{Pt}_{6}$ cluster. In addition, we will discuss dependences of the interaction energies on size of clusters whose number of contained Pt atoms $(k)$ being smaller than 6. Figures 5-7 show optimized structures for $\mathrm{Pt}_{6}$ cluster adsorbed on the mono-, di-, and tri-vacancy-type defects, respectively.

Several modes for the cluster bindings were considered. For example, we obtained six optimized geometries for a $\mathrm{Pt}_{6}$ cluster binding into the mono-vacancy-type defect in Figure 5. The four $\mathrm{Pt}_{6}-\mathrm{C}_{95} \mathrm{H}_{26}$ structures displayed in Figure 5 are relatively stable in energy. In general, stable $\mathrm{Pt}_{k}-\mathrm{C}_{95} \mathrm{H}_{26}$ structures have a $\mathrm{Pt}_{k-1}$ moiety contained in stable $\mathrm{Pt}_{k-1}-\mathrm{C}_{95} \mathrm{H}_{26}$ structures. Of course, there are other possibilities for $\mathrm{Pt}_{k}$ binding modes. However, our computational resource is limited, reluctantly we did not obtain other optimized geometries. We evaluated the binding energy in each configuration defined as $\left[E_{\text {bind }}=E_{\text {total }}\left(\mathrm{Pt}_{k}-\mathrm{C}_{96-n} \mathrm{H}_{26}\right)-E_{\text {total }}\left(\mathrm{C}_{96-n} \mathrm{H}_{26}\right)-E_{\text {total }}\left(\mathrm{Pt}_{k}\right)\right]$, where $k$ ranges from 1 to 6 (Tables 3-8).

Figure 5. Optimized geometries for $\mathrm{Pt}_{6}$ cluster on the mono-vacancy-type defect in the singlet state $\left(\mathrm{Pt}_{6}-\mathrm{C}_{95} \mathrm{H}_{26}\right)$. Optimized bond lengths are given in Table 3.

$\mathrm{Pt}_{6}(\mathrm{i})-\mathrm{C}_{95} \mathrm{H}_{26}(\mathrm{~A})$

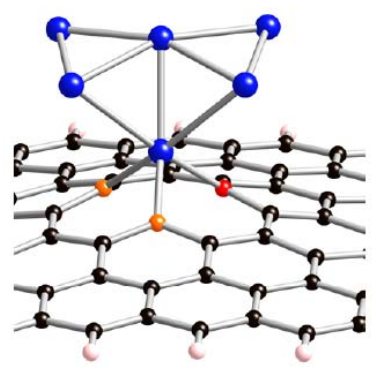

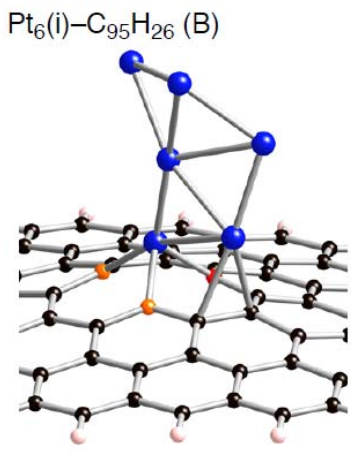

$\mathrm{Pt}_{6}(\mathrm{ii})-\mathrm{C}_{95} \mathrm{H}_{26}(\mathrm{C})$

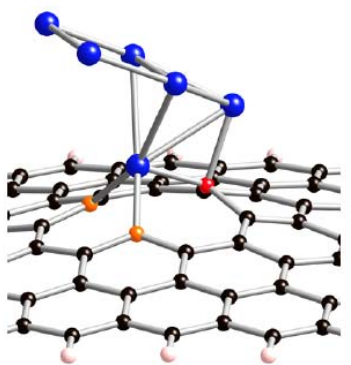


Figure 5. Cont.
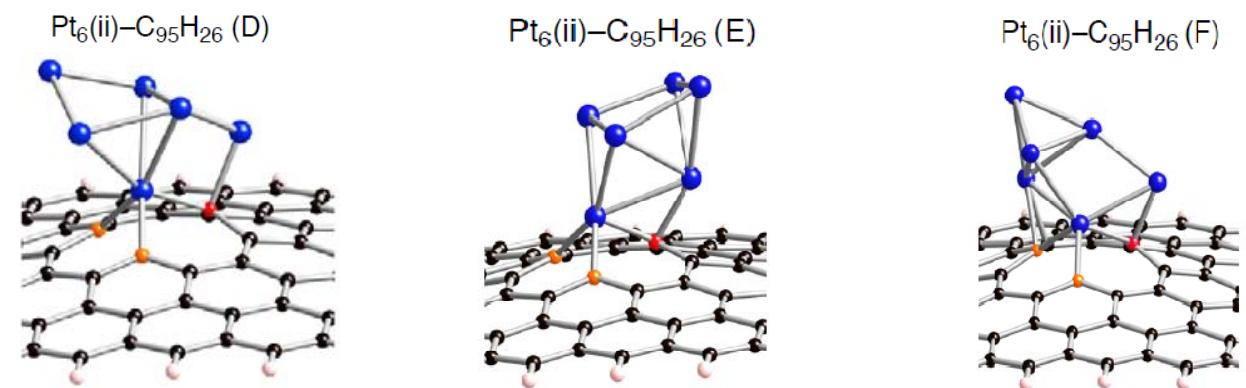

Table 3. Key parameters of $\mathrm{Pt}_{k}$ on mono-vacancy defect $\left(\mathrm{C}_{95} \mathrm{H}_{26}\right)(k$ is 1 or 6$)$ in Figure 5. Separations of a $\mathrm{Pt}$ atom from orange atoms (Pt-C(orange)) and those from the red atom (Pt-C(red)). Separations of carbon atoms from a Pt atom except for the nearest Pt atom (other Pt-C), and those between the two orange atoms (C-C). Bond lengths are in $\AA$. The $E_{\text {bind }}$ and $\Delta E\left(\mathrm{Pt}_{k}\right)$ values are given in $\mathrm{kcal} / \mathrm{mol}$. Their definition was given in the text.

\begin{tabular}{|c|c|c|c|c|c|c|}
\hline & $E_{\text {bind }}$ & Pt-C(orange) & Pt-C(red) & other Pt-C & C-C Bond & $\Delta E\left(\mathrm{Pt}_{\mathrm{k}}\right)$ \\
\hline $\mathbf{P t}_{1}$ & -145.7 & $1.953,1.954$ & 1.942 & - & 2.764 & - \\
\hline $\mathbf{P t}_{6}(\mathbf{i})-(\mathrm{A})$ & -152.0 & $1.986,1.988$ & 1.968 & - & 2.745 & 4.2 \\
\hline $\mathbf{P t}_{6}(\mathbf{i})-(\mathrm{B})$ & -146.6 & $1.947,1.968$ & 1.958 & 2.215 & 2.768 & 16.8 \\
\hline $\mathbf{P t}_{6}(\mathrm{ii})-(\mathrm{C})$ & -151.6 & $1.980,1.981$ & 1.991 & 2.074 & 2.728 & 17.4 \\
\hline $\mathbf{P t}_{6}(\mathrm{ii})-(\mathrm{D})$ & -157.1 & $1.983,1.983$ & 2.010 & 2.114 & 2.729 & 8.1 \\
\hline $\mathbf{P t}_{6}(\mathrm{ii})-(\mathrm{E})$ & -136.7 & $1.978,1.976$ & 1.991 & $2.200,2.083,2.252$ & 2.803 & 15.3 \\
\hline $\mathrm{Pt}_{6}(\mathrm{ii})-(\mathrm{F})$ & -143.4 & $1.986,1.977$ & 1.982 & 2.113 & 2.740 & 6.3 \\
\hline
\end{tabular}

Figure 6. Optimized geometries for $\mathrm{Pt}_{6}$ cluster on the di-vacancy-type defect in the singlet state $\left(\mathrm{Pt}_{6}-\mathrm{C}_{94} \mathrm{H}_{26}\right)$. Optimized bond lengths are given in Table 4.
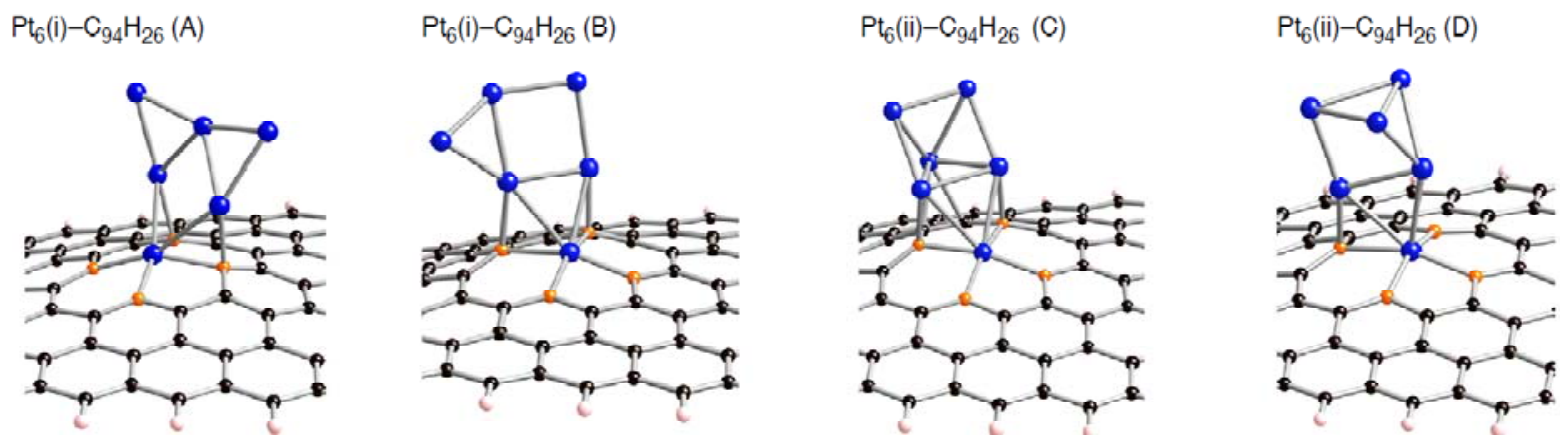

Table 4. Key parameters of $\mathrm{Pt}_{k}$ on di-vacancy defect $\left(\mathrm{C}_{94} \mathrm{H}_{26}\right)(k$ is 1 or 6) in Figure 6. Separations of a $\mathrm{Pt}$ atom from orange atoms ( $\mathrm{Pt}-\mathrm{C}$ (orange)), those of carbon atoms from a $\mathrm{Pt}$ atom except for the nearest $\mathrm{Pt}$ atom (other $\mathrm{Pt}-\mathrm{C}$ ), and those between the two orange atoms (C-C). Bond lengths are in $\AA$. The $E_{\text {bind }}$ and $\Delta E\left(\mathrm{Pt}_{k}\right)$ values are given in $\mathrm{kcal} / \mathrm{mol}$.

\begin{tabular}{|c|c|c|c|c|c|}
\hline & $E_{\text {bind }}$ & Pt-C(orange) & other Pt-C & C-C Bond & $\Delta E\left(\mathrm{Pt}_{\mathrm{k}}\right)$ \\
\hline $\mathbf{P t}_{1}$ & -106.1 & $1.999,1.985,1.999,1.985$ & - & $2.846,2.846$ & - \\
\hline $\mathbf{P t}_{6}(\mathbf{i})-(\mathbf{A})$ & -106.7 & $2.010,2.001,2.091,2.117$ & $2.088,2.033$ & $2.810,2.940$ & 12.7 \\
\hline $\mathrm{Pt}_{6}(\mathrm{i})-(\mathrm{B})$ & -106.3 & $2.014,2.101,2.109,2.008$ & $2.087,2.108$ & $2.918,2.921$ & 14.8 \\
\hline $\mathrm{Pt}_{6}$ (ii)-(C) & -94.5 & $2.014,2.119,2.088,2.005$ & $2.206,2.314,2.084,2.119$ & $2.928,2.921$ & 17.3 \\
\hline $\mathrm{Pt}_{6}(\mathrm{ii})-(\mathrm{D})$ & -85.1 & $1.994,2.021,2.036,2.114$ & 2.040 & $2.836,2.941$ & 17.9 \\
\hline
\end{tabular}


Figure 7. Optimized geometries for $\mathrm{Pt}_{6}$ cluster on the tri-vacancy-type defect in the triplet state $\left(\mathrm{Pt}_{6}-\mathrm{C}_{93} \mathrm{H}_{26}\right)$. Optimized bond lengths are given in Table 5.
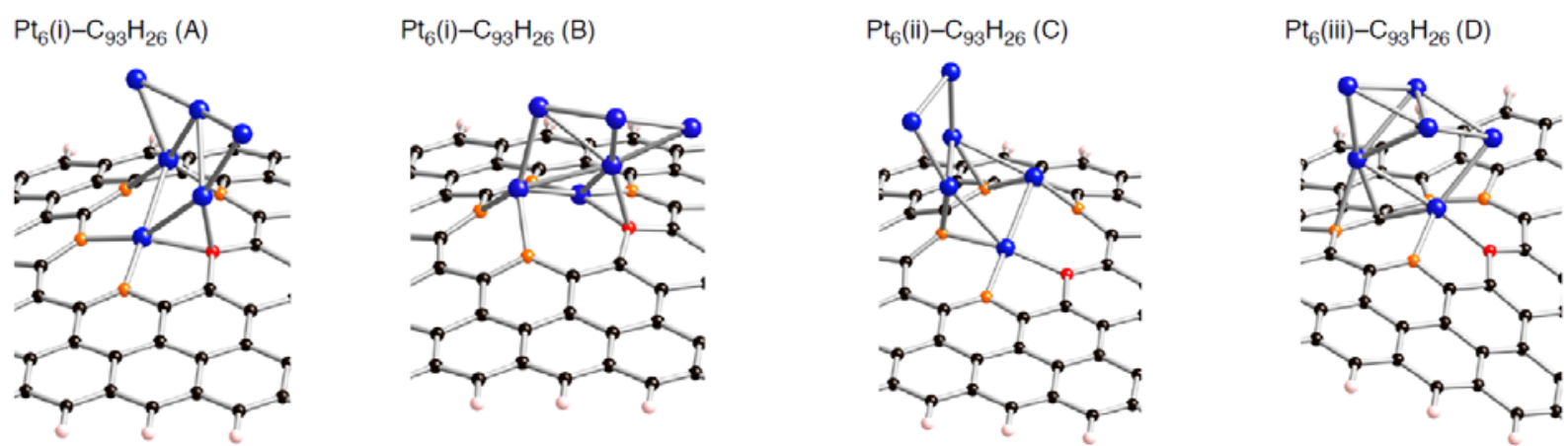

Table 5. Key parameters of $\mathrm{Pt}_{k}$ on tri-vacancy defect $\left(\mathrm{C}_{93} \mathrm{H}_{26}\right)(k$ is 1 or 6$)$ in Figure 7. Separations of a Pt atom from orange atoms (Pt-C(orange)) and those from the red atom (Pt-C(red)). Separations of carbon atoms from a Pt atom except for the nearest Pt atom (other Pt-C), and those between the two orange atoms (C-C). Bond lengths are in $\AA$. The $E_{\text {bind }}$ and $\Delta E\left(\mathrm{Pt}_{k}\right)$ values are given in $\mathrm{kcal} / \mathrm{mol}$.

\begin{tabular}{lcccccc}
\hline & $\boldsymbol{E}_{\text {bind }}$ & Pt-C(orange) & Pt-C(red) & other Pt-C & C-C Bond & $\boldsymbol{\Delta} \boldsymbol{E}\left(\mathbf{P t}_{\mathbf{k}} \mathbf{)}\right.$ \\
\hline $\mathbf{P t}_{\mathbf{1}}$ & -162.6 & $2.114,2.333,2.097,2.641$ & 2.059 & - & $2.637,2.641$ & - \\
$\mathbf{P t}_{\mathbf{6}}(\mathbf{i})-(\mathbf{A})$ & -198.2 & $1.992,1.959,1.971,1.969$ & 2.105 & 2.054 & $2.753,2.830$ & 12.2 \\
$\mathbf{P t}_{\mathbf{6}}(\mathbf{i})-(\mathbf{B})$ & -193.4 & $2.006,1.988,1.974,1.938$ & 2.144 & 2.130 & $2.825,2.746$ & 5.9 \\
$\mathbf{P t}_{\mathbf{6}}(\mathbf{i i ) - ( C )}$ & -188.4 & $1.971,2.081,1.970,1.969$ & 2.046 & $2.378,2.217,2.107$ & $2.924,2.922$ & 20.0 \\
Pt $_{\mathbf{6}}$ (ii)-(D) & -142.0 & $2.006,2.015$ & 2.021 & $2.130,2.231$ & 2.710 & 17.9 \\
\hline
\end{tabular}

Corresponding optimized structures for the smaller $\mathrm{Pt}_{k}$ clusters adsorbed $(k=2,3,4$, and 5) are also displayed in Figures 8-10.

Figure 8. Optimized geometries for $\mathrm{Pt}_{k}$ cluster $(k=2 \sim 5)$ on the mono-vacancy-type defect in the singlet state $\left(\mathrm{Pt}_{k}-\mathrm{C}_{95} \mathrm{H}_{26}\right)$. Optimized bond lengths are given in Table 6.
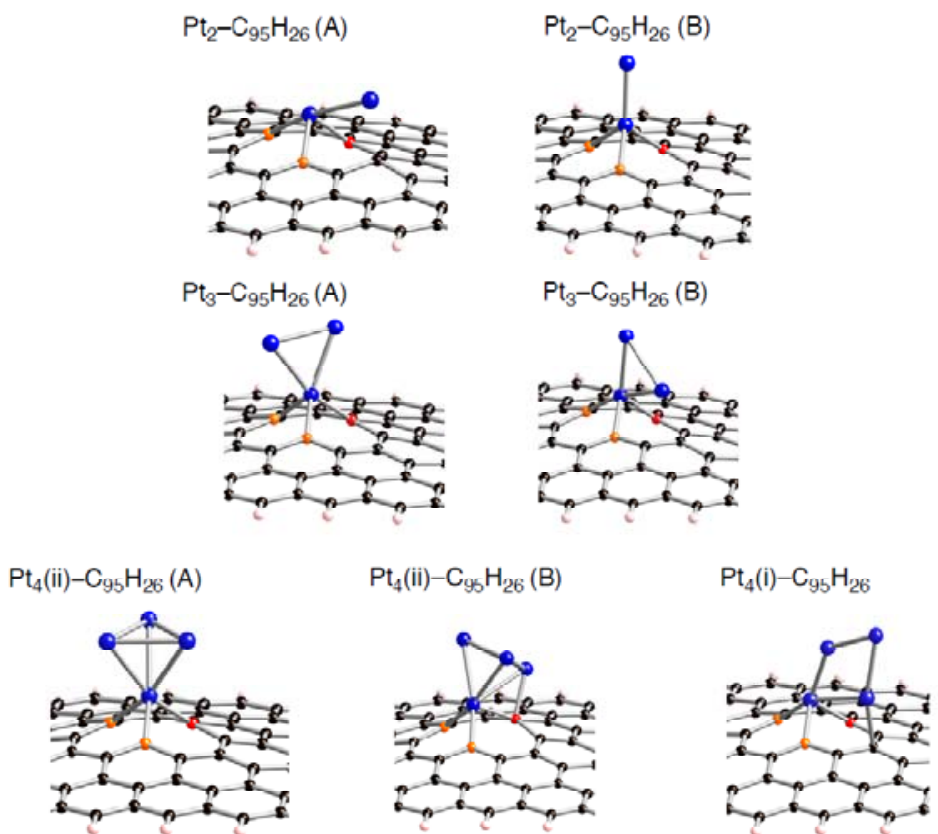
Figure 8. Cont.
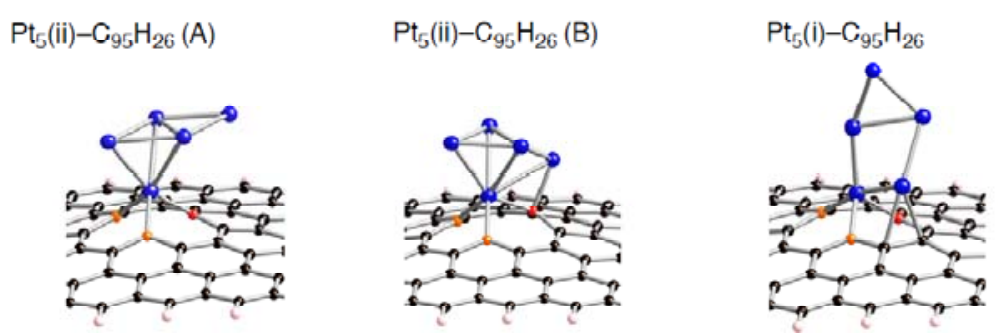

Table 6. Key parameters of $\mathrm{Pt}_{k}$ on mono-vacancy defect $\left(\mathrm{C}_{95} \mathrm{H}_{26}\right)(k=2 \sim 5)$ in Figure 8.

\begin{tabular}{lcccccc}
\hline & $\boldsymbol{E}_{\text {bind }}$ & Pt-C(orange) & Pt-C(red) & other Pt-C & C-C Bond & $\Delta \boldsymbol{E}\left(\mathbf{P t}_{\boldsymbol{k}} \mathbf{)}\right.$ \\
\hline $\mathbf{P t}_{\mathbf{2}}$-(A) & -131.7 & $1.964,2.006$ & 1.969 & - & 2.755 & 29.6 \\
$\mathbf{P t}_{\mathbf{2}}$-(B) & -146.1 & $1.965,1.965$ & 1.942 & - & 2.743 & 9.0 \\
$\mathbf{P t}_{\mathbf{3}}$-(A) & -132.4 & $1.971,1.972$ & 1.971 & - & 2.715 & 0.9 \\
$\mathbf{P t}_{\mathbf{3}}$-(B) & -126.9 & $1.952,1.976$ & 1.962 & - & 2.790 & 2.5 \\
$\mathbf{P t}_{\mathbf{4}}$ (ii)-(A) & -139.7 & $1.983,1.984$ & 1.967 & - & 2.759 & 7.4 \\
$\mathbf{P t}_{\mathbf{4}}$ (ii)-(B) & -140.0 & $1.981,1.987$ & 1.987 & 2.054 & 2.743 & 7.4 \\
$\mathbf{P t}_{\mathbf{4}}$ (i) & -128.3 & $1.953,1.966$ & 1.960 & 2.227 & 2.757 & 19.8 \\
$\mathbf{P t}_{\mathbf{5}}$ (ii)-(A) & -140.5 & $1.976,1.976$ & 1.980 & - & 2.753 & 4.3 \\
$\mathbf{P t}_{\mathbf{5}}$ (ii)-(B) & -147.8 & $1.982,1.982$ & 2.002 & 2.105 & 2.741 & 5.4 \\
$\mathbf{P t}_{\mathbf{5}}$ (i) & -132.4 & $1.947,1.966$ & 1.972 & $2.211,2.275$ & 2.790 & 4.6 \\
\hline
\end{tabular}

Figure 9. Optimized geometries for $\operatorname{Pt}_{k}$ cluster $(k=2 \sim 5)$ on the di-vacancy-type defect in the singlet state $\left(\mathrm{Pt}_{k}-\mathrm{C}_{94} \mathrm{H}_{26}\right)$. Optimized bond lengths are given in Table 7.

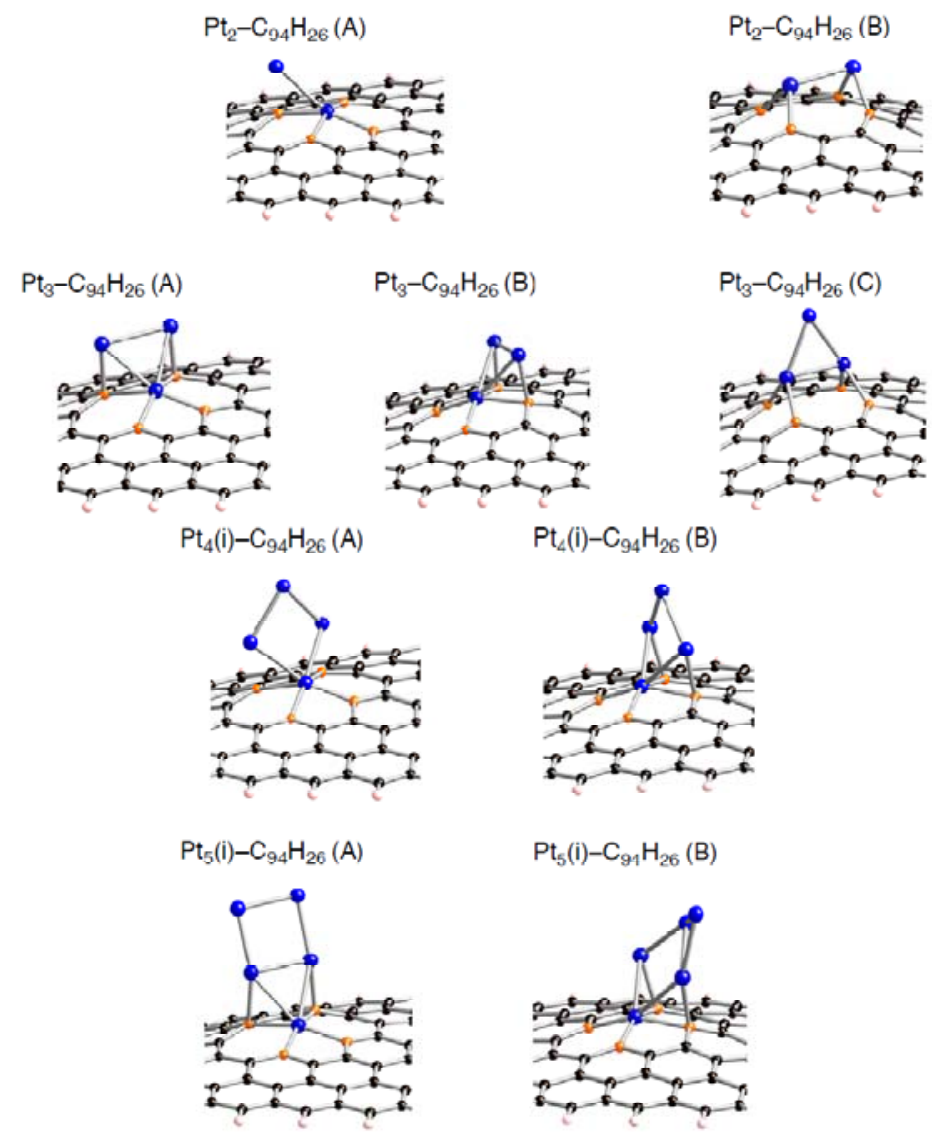


Table 7. Key parameters of $\mathrm{Pt}_{k}$ on di-vacancy defect $\left(\mathrm{C}_{94} \mathrm{H}_{26}\right)(k=2 \sim 5)$ in Figure 9.

\begin{tabular}{|c|c|c|c|c|c|}
\hline & $E_{\text {bind }}$ & Pt-C(orange) & other Pt-C & C-C Bond & $\Delta E\left(\mathbf{P t}_{k}\right)$ \\
\hline $\mathbf{P t}_{2}$-(A) & -91.2 & $1.999,2.028,2.038,2.066$ & - & $2.831,2.904$ & 10.6 \\
\hline $\mathbf{P t}_{2}-(\mathrm{B})$ & -59.2 & $1.934,1.935,1.997,1.997$ & - & $2.786,2.740$ & 7.1 \\
\hline $\mathbf{P t}_{3}-\mathbf{( A )}$ & -70.9 & $2.025,2.118,2.025,2.119$ & $2.045,2.046$ & $2.893,2.893$ & 9.6 \\
\hline $\mathbf{P t}_{3}-(\mathrm{B})$ & -63.2 & $1.990,2.013,2.125,2.199$ & $2.081,2.082$ & $2.791,2.976$ & 7.0 \\
\hline $\mathbf{P t}_{3}-(\mathbf{C})$ & -57.6 & $1.972,1.987,1.971,1.986$ & - & $2.690,2.690$ & 1.1 \\
\hline $\mathbf{P t}_{4}(\mathbf{i})-(\mathbf{A})$ & -84.8 & $2.034,2.035,2.101,2.100$ & $2.053,2.054$ & $2.852,2.853$ & 6.4 \\
\hline $\mathbf{P t}_{4}(\mathbf{i})-(\mathrm{B})$ & -75.8 & $2.004,2.005,2.064,2.134$ & $2.067,2.066$ & $2.786,2.896$ & 4.7 \\
\hline $\mathbf{P t}_{5}(\mathbf{i})-(\mathbf{A})$ & -93.4 & $2.005,2.006,2.085,2.099$ & $2.122,2.138$ & $2.917,2.923$ & 12.3 \\
\hline $\mathbf{P t}_{5}(\mathbf{i})-(\mathrm{B})$ & -81.3 & $1.991,2.001,2.113,2.123$ & $2.053,2.082$ & $2.806,2.932$ & 13.4 \\
\hline
\end{tabular}

Figure 10. Optimized geometries for $\mathrm{Pt}_{k}$ cluster $(k=2 \sim 5)$ on the tri-vacancy-type defect in the singlet state $\left(\mathrm{Pt}_{k}-\mathrm{C}_{93} \mathrm{H}_{26}\right)$. Optimized bond lengths are given in Table 8.
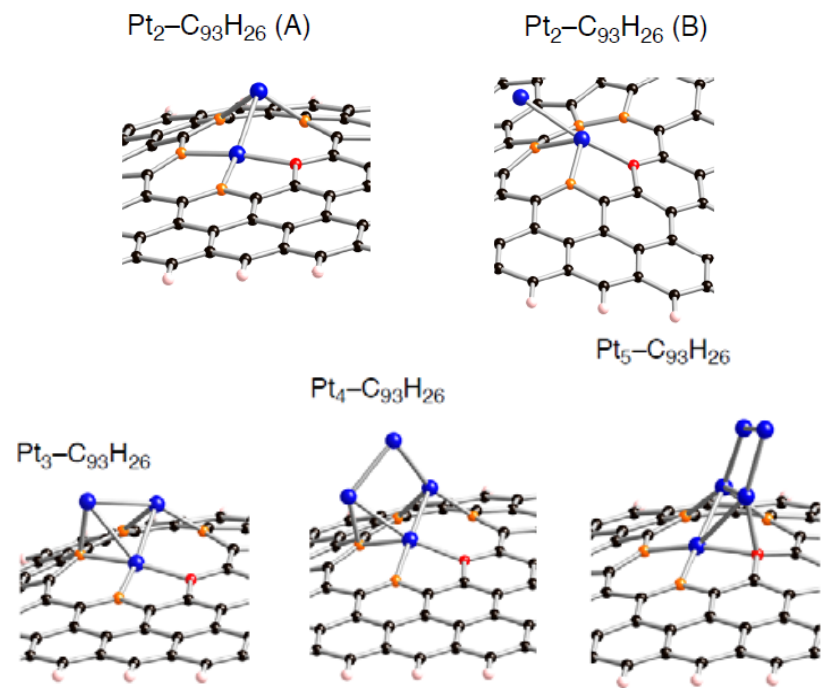

Table 8. Key parameters of $\mathrm{Pt}_{k}$ on tri-vacancy defect $\left(\mathrm{C}_{93} \mathrm{H}_{26}\right)(k=2 \sim 5)$ in Figure 10. Separations of a Pt atom from orange atoms (Pt-C(orange)) and those from the red atom (Pt-C(red)). Separations of carbon atoms from a Pt atom except for the nearest Pt atom (other Pt-C), and those between the two orange atoms (C-C). Bond lengths are in $\AA$. The $E_{\text {bind }}$ and $\Delta E\left(\mathrm{Pt}_{k}\right)$ values are given in $\mathrm{kcal} / \mathrm{mol}$. Their definition was given in the text.

\begin{tabular}{lcccccc}
\hline & $\boldsymbol{E}_{\text {bind }}$ & Pt-C(orange) & Pt-C(red) & other Pt-C & C--C Bond & $\Delta \boldsymbol{E}(\mathbf{P t}$ \\
$\left.\mathbf{k}_{\boldsymbol{k}}\right)$ \\
\hline $\mathbf{P t}_{\mathbf{2}}$-(A) & -172.3 & $1.944,1.968,1.988,1.950$ & 2.038 & - & $2.839,2.852$ & 22.0 \\
$\mathbf{P t}_{\mathbf{2}}$-(B) & -132.0 & $2.002,1.985$ & 2.009 & 2.021 & $2.874,1.630$ & 8.3 \\
$\mathbf{P t}_{\mathbf{3}}$ & -167.5 & $1.948,1.964,1.989,2.124$ & 2.021 & 2.067 & $2.999,2.832$ & 9.8 \\
$\mathbf{P t}_{\mathbf{4}}$ & -180.3 & $1.978,2.068,1.973,1.981$ & 2.046 & 2.050 & $2.897,2.704$ & 3.6 \\
$\mathbf{P t}_{\mathbf{5}}$ & -173.0 & $1.950,1.976,1.934,1.997$ & 2.099 & - & $2.840,2.750$ & 13.9 \\
\hline
\end{tabular}

Here $E_{\text {total }}\left(\mathrm{Pt}_{k}-\mathrm{C}_{96-n} \mathrm{H}_{26}\right)$ is the total energy of an optimized $\mathrm{C}_{96-n} \mathrm{H}_{26}$ geometry, $E_{\text {total }}\left(\mathrm{C}_{96-n} \mathrm{H}_{26}\right)$ is that of the optimized $\mathrm{C}_{96-n} \mathrm{H}_{26}$ geometry, and $E_{\text {total }}\left(\mathrm{Pt}_{k}\right)$ is that of the optimized $\mathrm{Pt}_{k}$ cluster. For the DFT calculations of the binding energies, a counterpoise correction for basis set superposition error (BSSE) was included [55]. When an $E_{\text {bind }}$ value has a negative sign, the binding of a Pt cluster or the Pt atom 
into $\mathrm{C}_{96-n} \mathrm{H}_{26}$ is energetically preferable. As shown in Tables $3-5$, the calculated $E_{\text {bind }}$ values in the single Pt addition are similar to those reported in [35]. These similarities verify the reliability of our DFT results.

Looking at the $E_{\text {bind }}$ values, the bindings of a $\mathrm{Pt}_{k}$ cluster into the $\mathrm{sp}^{2}$ surface are strongly facilitated by introducing vacancy-type defects. In fact, their stabilizing energies $\left(-E_{\text {bind }}\right)$ in stable $\mathrm{Pt}_{k}-\mathrm{C}_{95} \mathrm{H}_{26}$ structures are around $150 \mathrm{kcal} / \mathrm{mol}$. These values are much larger than the pristine cases (about $50 \mathrm{kcal} / \mathrm{mol}$ [22]). Similar enhancement in the stabilization energies was also found in the $\mathrm{Pt}_{k}-\mathrm{C}_{94} \mathrm{H}_{26}$ and $\mathrm{Pt}_{k}-\mathrm{C}_{93} \mathrm{H}_{26}$ structures. Judging from the $\mathrm{E}_{\text {bind }}$ values, reactivity of vacancy-type defects toward $\mathrm{Pt}$ clusters declines in the order: tri-vacancy $>$ mono-vacancy $>$ di-vacancy. These results suggest that the tri-vacancy defect is more suitable for binding of Pt clusters into carbon surface rather than the mono- and di-vacancy defects.

From Tables 3-8, we see different behaviors between the three types of defect in terms of dependences of the $E_{\text {bind }}$ values on Pt cluster size. Most stable $\mathrm{Pt}_{k}-\mathrm{C}_{95} \mathrm{H}_{26}$ structures except for $\mathrm{Pt}_{3}-\mathrm{C}_{95} \mathrm{H}_{26}$ have $\mathrm{E}_{\text {bind }}$ values similar to that in $\mathrm{Pt}_{1}-\mathrm{C}_{95} \mathrm{H}_{26}$. In contrast, the $E_{\text {bind }}$ values in $\mathrm{Pt}_{k}-\mathrm{C}_{94} \mathrm{H}_{26}$ and $\mathrm{Pt}_{k}-\mathrm{C}_{93} \mathrm{H}_{26}$ are deviated from those in $\mathrm{Pt}_{1}-\mathrm{C}_{94} \mathrm{H}_{26}$ and $\mathrm{Pt}_{1}-\mathrm{C}_{93} \mathrm{H}_{26}$. When a $\mathrm{Pt}_{k}$ cluster binds into the di-vacancy-defect, their $\mathrm{E}_{\text {bind }}$ values are smaller than the $\mathrm{Pt}_{1}-\mathrm{C}_{94} \mathrm{H}_{26}$ value. However, these absolute values increase gradually with an increase of the cluster size, and seem to converge to the $\mathrm{Pt}_{1}-\mathrm{C}_{94} \mathrm{H}_{26}$ value at $k=6$. In the $\mathrm{Pt}_{k}-\mathrm{C}_{93} \mathrm{H}_{26}$ cases, the $\mathrm{E}_{\text {bind }}$ values, being around $180 \mathrm{kcal} / \mathrm{mol}$, are always larger than the $\mathrm{Pt}_{1}-\mathrm{C}_{93} \mathrm{H}_{26}$ value.

To understand the energetics in the optimized $\mathrm{Pt}_{k}-\mathrm{C}_{96-n} \mathrm{H}_{26}$ structures (Tables 3-8), let us first look at in detail geometrical features of $\mathrm{Pt}_{1}-\mathrm{C}_{96-n} \mathrm{H}_{26}$. These key geometrical parameters in the $\mathrm{Pt}_{1-} \mathrm{C}_{96-n} \mathrm{H}_{26}$ configurations (lengths of newly formed Pt-C bonds and of lengthening CC bonds) are listed in Tables 3-5.

In these tables, we can distinguish two types of the formed $\mathrm{Pt}-\mathrm{C}$ bond, by whether a $\mathrm{Pt}$ atom binds into orange or red atoms. When the single Pt atom binds into the mono-vacancy defect, it inserts between the orange atoms in the five-membered ring, and then two P-C(orange) bonds are formed newly. As a result of the Pt addition, the separation between the orange atoms lengthens from 1.754 to $2.764 \AA$. At the same time, the Pt atom also coordinates to the unsaturated red atom. The binding $\mathrm{Pt}$ atom lifts from the $\mathrm{sp}^{2}$ surface, because the hole is not large enough to accommodate the $\mathrm{Pt}$ atom. Similar Pt lifting can be seen in the $\mathrm{Pt}_{1}-\mathrm{C}_{94} \mathrm{H}_{26}$ configuration, where the $\mathrm{Pt}$ atom inserts between orange atoms in both five-membered rings, and it breaks the connections. The degree of $\mathrm{Pt}$ lifting in $\mathrm{Pt}_{1}-\mathrm{C}_{94} \mathrm{H}_{26}$ is less significant than that in $\mathrm{Pt}_{1}-\mathrm{C}_{95} \mathrm{H}_{26}$, due to relatively larger hole in $\mathrm{C}_{94} \mathrm{H}_{26}$.

In contrast, the hole of $\mathrm{C}_{93} \mathrm{H}_{26}$, surrounded by ten carbon atoms, can house the $\mathrm{Pt}$ atom, and therefore the binding $\mathrm{Pt}$ atom is on the $s p^{2}$ surface. Then, four Pt-C bonds are formed, accompanying the cleavage of the bonds between orange atoms in the five-membered rings. Moreover, the Pt binding into the unsaturated $\mathrm{C}$ atom was also seen. When a $\mathrm{Pt}_{k}$ cluster binds into a vacancy-type defect, slightly longer separations of the nearest Pt atom from reactive (orange and red) atoms were found. Despite the stabilization operated between a $\mathrm{Pt}_{k}$ cluster and $\mathrm{C}_{96-n} \mathrm{H}_{26}$, slightly longer $\mathrm{Pt}-\mathrm{C}$ bonds imply weakening interactions of the nearest $\mathrm{Pt}$ atom from the reactive carbon atoms compared with $\mathrm{Pt}_{1}-\mathrm{C}_{96-n} \mathrm{H}_{26}$ case.

Compensating the weakening of the interactions, remaining $\mathrm{Pt}$ atoms of a clusters are additionally bound to carbon atoms of a defective site to maximize the Pt-C interactions. Then their clusters are more or less deformed from the most stable configuration in the gas-phase [56-58]. The degree of cluster deformation was estimated by using $\Delta E\left(\mathrm{Pt}_{k}\right)$, defined as $\left[E\left(\mathrm{Pt}_{k}\right.\right.$ on surface $\left.)-E\left(\mathrm{Pt}_{k}\right)\right]$, where 
$E\left(\mathrm{Pt}_{k}\right.$ on surface $)$ is the total energy of $\mathrm{Pt}_{k}$ cluster taken from an optimized $\mathrm{Pt}_{k}-\mathrm{C}_{96-n} \mathrm{H}_{26}$ structure and $E\left(\mathrm{Pt}_{k}\right)$ is that of the optimized geometry for the bare $\mathrm{Pt}_{k}$ cluster. Positive $\Delta E\left(\mathrm{Pt}_{k}\right)$ values in Tables 3-8 suggest destabilization from cluster deformation upon the interactions with a vacancy-type defect. Although we cannot find a clear correlation between $\mathrm{E}_{\text {bind }}$ and $\Delta E\left(\mathrm{Pt}_{k}\right)$ values, the balance between the stabilization from the Pt-C bond formation and the destabilization from the cluster deformation is a key in determining the stability. From Figures 5-7 and 11, we found clear differences between $\mathrm{Pt}_{k}-\mathrm{C}_{93} \mathrm{H}_{26}$ and $\mathrm{Pt}_{k}-\mathrm{C}_{95} \mathrm{H}_{26}\left(\mathrm{Pt}_{k}-\mathrm{C}_{94} \mathrm{H}_{26}\right)$ in terms of the number of $\mathrm{Pt}$ atoms binding directly into orange atoms in the defective site to cleave connections between adjacent orange atoms.

Figure 11. Optimized geometries for the singlet $\mathrm{Pt}$ atom on the mono-, di-, and tri-vacancy-type defects in the triplet state $\left(\mathrm{Pt}_{1}-\mathrm{C}_{95} \mathrm{H}_{26}, \mathrm{Pt}_{1}-\mathrm{C}_{94} \mathrm{H}_{26}\right.$, and $\mathrm{Pt}_{1}-\mathrm{C}_{93} \mathrm{H}_{26}$, respectively). Optimized bond lengths are given in Tables 3-5.
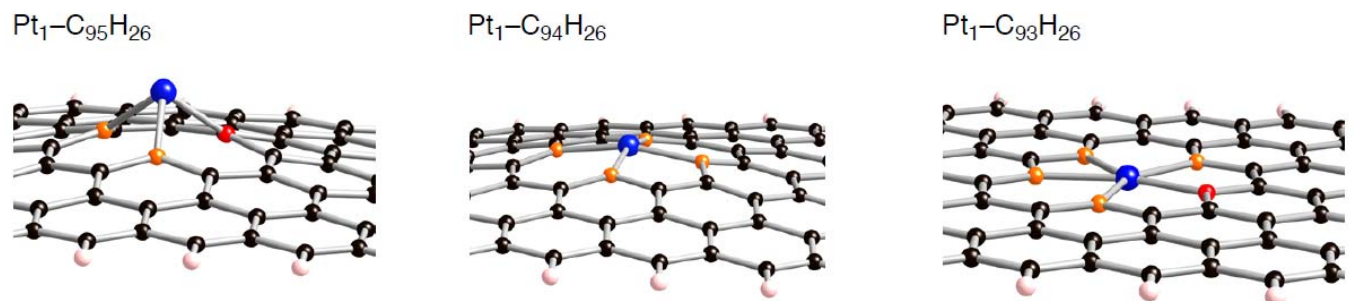

In $\mathrm{Pt}_{k}-\mathrm{C}_{95} \mathrm{H}_{26}\left(\mathrm{Pt}_{\mathrm{k}}-\mathrm{C}_{94} \mathrm{H}_{26}\right)$, one $\mathrm{Pt}$ atom participates in cleaving the orange connection(s), irrespective of the cluster size. In the tri-vacancy cases containing larger ten-membered ring, two $\mathrm{Pt}$ atoms in a cluster bind to the defective site to split two orange connections. The accommodation of two $\mathrm{Pt}$ atoms cannot be seen in the $\mathrm{Pt}_{1}-\mathrm{C}_{94} \mathrm{H}_{26}$ structure, and thus the significant enhanced stabilization in $\mathrm{Pt}_{k}-\mathrm{C}_{93} \mathrm{H}_{26}$ is understandable. Moreover the acceptability of the ten-membered-ring to trap Pt atoms differentiates $\mathrm{C}_{93} \mathrm{H}_{26}$ from $\mathrm{C}_{95} \mathrm{H}_{26}$ and $\mathrm{C}_{94} \mathrm{H}_{26}$ in terms of their reactivity toward $\mathrm{Pt}_{k}$ clusters. Due to the strong interactions between a $\mathrm{Pt}_{6}$ cluster and a vacancy-type defect, we can see unique orbital features, which cannot be seen in $\mathrm{C}_{96-n} \mathrm{H}_{26}$ (Figure 12).

In fact, $5 \mathrm{~d}(\mathrm{Pt})$-based orbitals, given by blue bars in Figure 12, appear in the frontier orbital regions of the $\mathrm{Pt}_{6}-\mathrm{C}_{94} \mathrm{H}_{26}$ and $\mathrm{Pt}_{6}-\mathrm{C}_{93} \mathrm{H}_{26}$ configurations. As the most striking case, we can see in Figure 13 that the $\mathrm{Pt}_{6}(\mathrm{i})-\mathrm{C}_{94} \mathrm{H}_{26}(\mathrm{~B})$ configuration has the HOMO and LUMO consisting of $5 \mathrm{~d}(\mathrm{Pt})$ orbitals. On the other hand, levels of $5 \mathrm{~d}(\mathrm{Pt})$-based orbitals in the $\mathrm{Pt}_{6}-\mathrm{C}_{95} \mathrm{H}_{26}$ strongly depend on their cluster-shape. In the $\mathrm{Pt}_{6}(\mathrm{i})-\mathrm{C}_{95} \mathrm{H}_{26}(\mathrm{~A})$ and $\mathrm{Pt}_{6}(\mathrm{ii})-\mathrm{C}_{95} \mathrm{H}_{26}(\mathrm{C})$ configurations, such $5 \mathrm{~d}(\mathrm{Pt})$-based orbital lies larger than $1.3 \mathrm{eV}$ above the LUMO, whereas the LUMO+1 consists of $5 \mathrm{~d}(\mathrm{Pt})$-based orbitals in the other $\mathrm{Pt}_{6}-\mathrm{C}_{95} \mathrm{H}_{26}$ configurations.

\subsubsection{Triplet State}

As shown in Figure 12, the all optimized geometries in the single state have relatively small HOMO-LUMO gaps $(0.29 \sim 0.40 \mathrm{eV})$. Thus, higher spin states can be energetically stable relative to the singlet states. Along the assumption, we obtained their triplet states, and estimated the energy difference between the two spin states $\left(\Delta \mathrm{E}_{\text {state }}\left(\mathrm{Pt}_{6}-\mathrm{C}_{96-n} \mathrm{H}_{26}\right)\right)$, as tabulated in Table 9. 
Figure 12. Orbital energies $(\mathrm{eV})$ in the frontier orbital region of the optimized $\mathrm{Pt}_{6}-\mathrm{C}_{95} \mathrm{H}_{26}$, $\mathrm{Pt}_{6}-\mathrm{C}_{94} \mathrm{H}_{26}$, and $\mathrm{Pt}_{6}-\mathrm{C}_{93} \mathrm{H}_{26}$ configurations whose structures are given in Figures 5-7. The HOMO-LUMO gaps are given. Orbitals originated from $5 \mathrm{~d}(\mathrm{Pt})$ orbitals are denoted by blue bars, and those with no or less $5 \mathrm{~d}(\mathrm{Pt})$ orbital contribution are denoted by black bars.

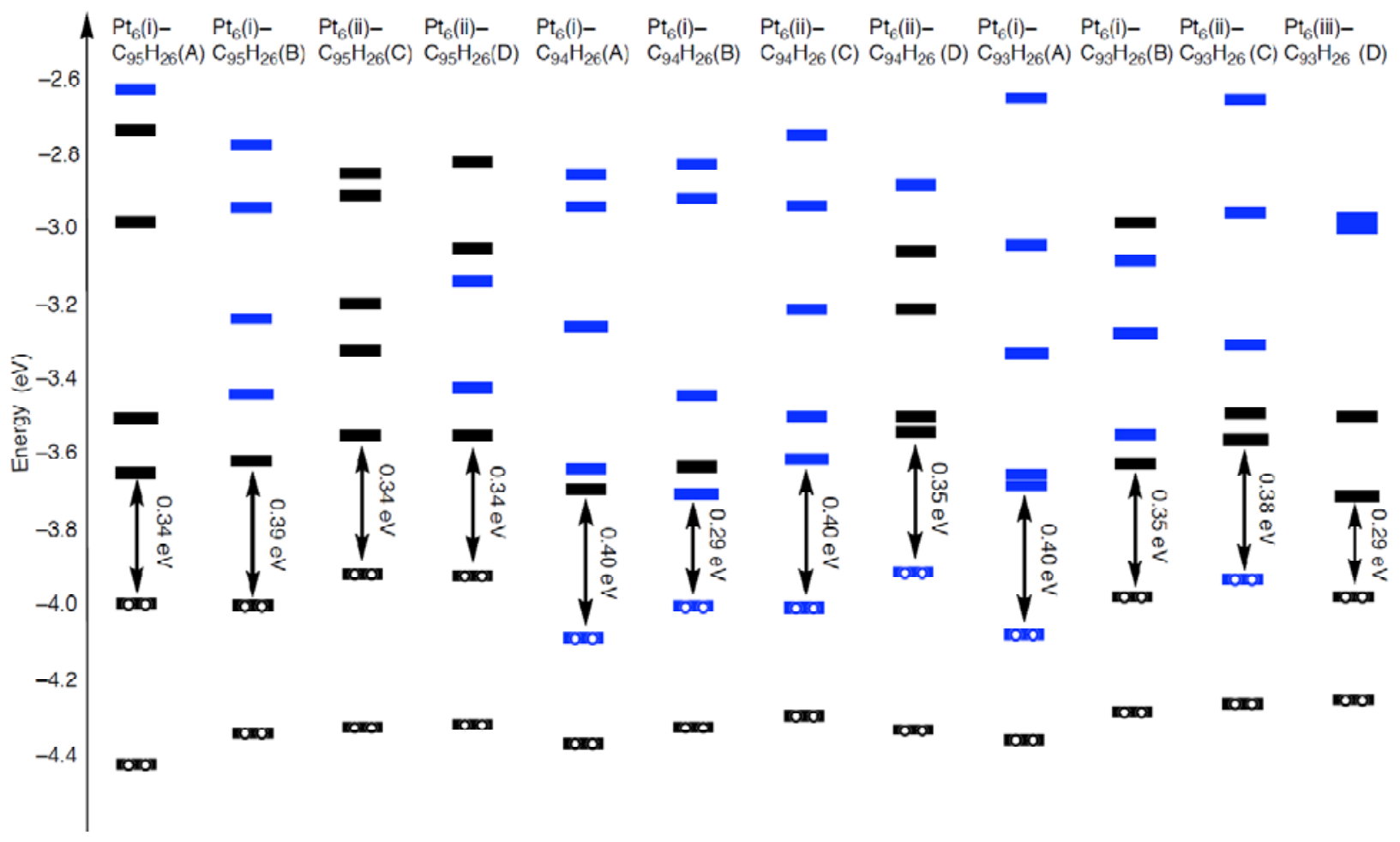

Figure 13. Frontier orbitals (the $\mathrm{HOMO}$ and LUMO) in the $\mathrm{Pt}_{6}(\mathrm{i})-\mathrm{C}_{94} \mathrm{H}_{26}(\mathrm{~B})$ configuration (Figure 6) are given as a representative $\mathrm{Pt}_{6}-\mathrm{C}_{96-n} \mathrm{H}_{26}$ configuration.
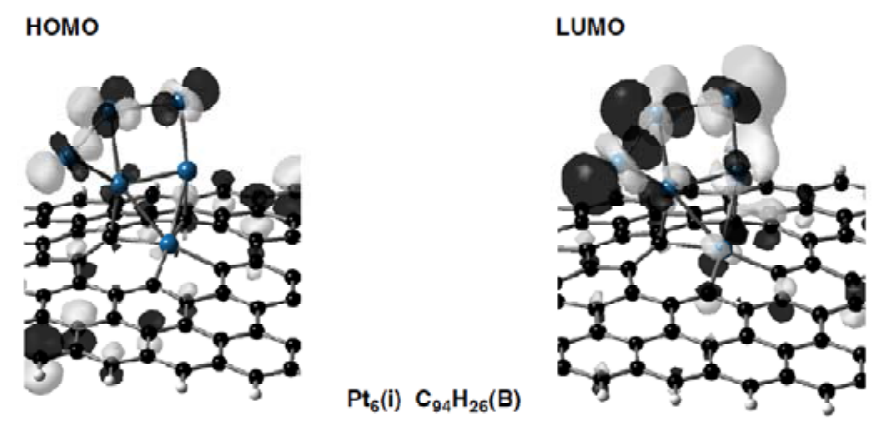

Table 9. Energy difference between the singlet and triplet states in the $\mathrm{Pt}_{6}-\mathrm{C}_{96-n} \mathrm{H}_{26}$ configurations $\left(\Delta \mathrm{E}_{\text {state }} \text { in } \mathrm{kcal} / \mathrm{mol}\right)^{\mathrm{a}}$.

\begin{tabular}{lcccc}
\hline & $\mathbf{P t}_{\mathbf{6}}(\mathbf{i})-(\mathbf{A})$ & $\mathbf{P t}_{\mathbf{6}}(\mathbf{i})-(\mathbf{B})$ & $\mathbf{P t}_{\mathbf{6}}(\mathbf{i i})$ & $\mathbf{P t}_{\mathbf{6}}(\mathbf{i i i})$ \\
\hline Clusters on $\mathbf{C}_{\mathbf{9 5}} \mathbf{H}_{\mathbf{2 6}}$ & -14.3 & -17.8 & -14.0 & $\mathrm{~b}$ \\
Clusters on $\mathbf{C}_{\mathbf{9 4}} \mathbf{H}_{\mathbf{2 6}}$ & -23.3 & -16.2 & -23.3 & -38.5 \\
Clusters on $\mathbf{C}_{\mathbf{9 3}} \mathbf{H}_{\mathbf{2 6}}$ & -15.0 & -23.7 & -13.7 & $\mathrm{~b}$ \\
\hline
\end{tabular}

${ }^{\mathrm{a}} \Delta E_{\text {state }}\left(\mathrm{Pt}_{6}-\mathrm{C}_{96-n} \mathrm{H}_{26}\right)=E_{\text {total }}($ triplet state $)-E_{\text {total }}($ singlet state $)$. Negative $\Delta E_{\text {state }}$ values indicate that the triplet state of a $\mathrm{Pt}_{6}-\mathrm{C}_{96-n} \mathrm{H}_{26}$ configuration is energetically stable relative to the singlet state. $\Delta \mathrm{E}_{\text {state }}$ in $\mathrm{kcal} / \mathrm{mol} ;{ }^{\mathrm{b}}$ we could not obtain the optimized geometry in the triplet state. 
Table 9 shows that their triplet spin states are energetically stable relative to the singlet states, as expected. According to DFT calculations, most $\mathrm{Pt}_{6}-\mathrm{C}_{96-n} \mathrm{H}_{26}$ configurations have radical $\mathrm{Pt}_{6}$ clusters on defective graphene patches As representative cases, spin density distributions on the $\mathrm{Pt}_{6}(\mathrm{i})$ cluster binding into $\mathrm{C}_{95} \mathrm{H}_{26}$ or $\mathrm{C}_{94} \mathrm{H}_{26}$ are shown in Figure 14. Figure 14 shows that substantial spin densities appear on the adsorbed clusters in the three $\mathrm{Pt}_{6}-\mathrm{C}_{96-n} \mathrm{H}_{26}$ configurations $\left(\mathrm{Pt}_{6}(\mathrm{i})-\mathrm{C}_{95} \mathrm{H}_{26}(\mathrm{~B})\right.$, and two $\mathrm{Pt}_{6}(\mathrm{i})-\mathrm{C}_{94} \mathrm{H}_{26}$ configurations), whereas the $\mathrm{Pt}_{6}(\mathrm{i})-\mathrm{C}_{95} \mathrm{H}_{26}(\mathrm{~A})$ configuration does not have such radical cluster due to the absence of $5 \mathrm{~d}(\mathrm{Pt}$ )-based frontier orbitals (Figure 12). In the three configurations with radical clusters, a variety of the spin density distributions was found. In the $\mathrm{Pt}_{6}(\mathrm{i})-\mathrm{C}_{95} \mathrm{H}_{26}(\mathrm{~B})$ and $\mathrm{Pt}_{6}(\mathrm{i})-\mathrm{C}_{94} \mathrm{H}_{26}(\mathrm{~B})$, the spin density distributions are strongly deviated from those in the bare $\mathrm{Pt}_{6}$ cluster, whereas the $\mathrm{Pt}_{6}(\mathrm{i})-\mathrm{C}_{94} \mathrm{H}_{26}(\mathrm{~B})$ has similar distributions. Furthermore, we found a relationship between spin densities of Pt clusters and those on the defective $\mathrm{sp}^{2}$ surface. When spin density distributions of the Pt cluster of a $\mathrm{Pt}_{6}-\mathrm{C}_{96-n} \mathrm{H}_{26}$ configuration are (not) similar to the bare case, spin densities are (not) delocalized over the carbon surface. Similar tendencies were found in spin density distributions of the stable triplet $\mathrm{Pt}_{13}-\mathrm{C}_{96-n} \mathrm{H}_{26}$ configurations [59], because radical Pt clusters exist on the defective graphene patches as shown in Figure 15.

Figure 14. Spin density distributions of representative $\mathrm{Pt}_{6}-\mathrm{C}_{96-n} \mathrm{H}_{26}$ configurations $\left(\mathrm{Pt}_{6}(\mathrm{i})\right.$ cluster on $\mathrm{C}_{95} \mathrm{H}_{26}$ or $\mathrm{C}_{94} \mathrm{H}_{26}$ in two binding fashions, displayed in Figures 5 and 6). Isosurface $\alpha$ - and $\beta$-spins are given by pink and blue, respectively.

$\mathrm{Pt}_{6}(\mathrm{i})-\mathrm{C}_{95} \mathrm{H}_{26}(\mathrm{~A})$

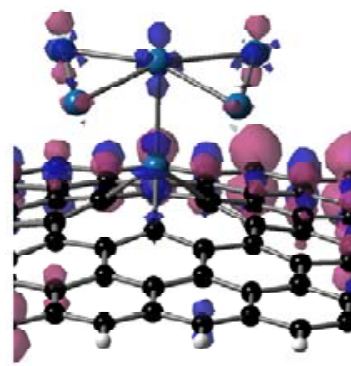

$\mathrm{Pt}_{6}(\mathrm{i})-\mathrm{C}_{95} \mathrm{H}_{26}(\mathrm{~B})$

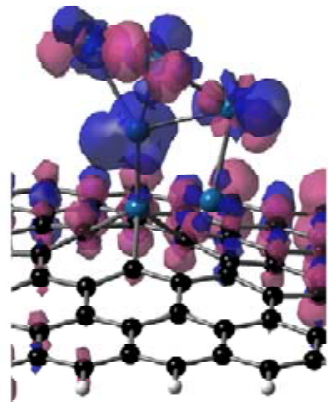

$\mathrm{Pt}_{6}(\mathrm{i})-\mathrm{C}_{94} \mathrm{H}_{26}(\mathrm{~A})$

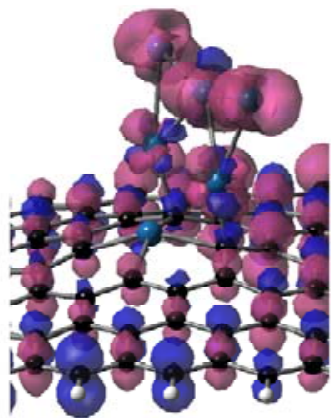

$\mathrm{Pt}_{6}(\mathrm{i})-\mathrm{C}_{94} \mathrm{H}_{26}(\mathrm{~B})$

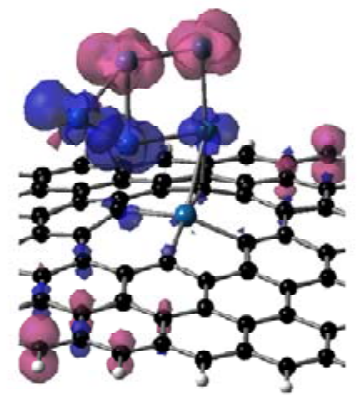

Finally, let us compare the spin density distributions on $\mathrm{Pt}_{6}$ clusters on defective $\mathrm{sp}^{2}$ surfaces (Figure 14) with the pristine case (Figure 2). As mentioned above, spin density maps on $\mathrm{Pt}_{6}$ cluster on pristine $\mathrm{C}_{96} \mathrm{H}_{26}$ are similar to those in the bare cluster. However, such similarity cannot be always found in the defective graphene cases. The different tendencies come from whether underlying carbon atoms have radical characters or not in Figures 2 and 4. In the pristine patch, underlying carbon atoms do not have radical characters, and they cannot perturb spin density distributions of the absorbed cluster. In contrast, unpaired electrons exist on underlying carbon atoms in the defective sites, and thus spin density distributions of the adsorbed clusters are modulated by the $\mathrm{Pt}-\mathrm{C}$ interactions. Therefore, perturbation of the radical $\mathrm{sp}^{2}$ surface by introduction of vacancy-type defects can change characters of adsorbed Pt clusters. 
Figure 15. Spin density distributions of representative $\mathrm{Pt}_{13}-\mathrm{C}_{96-n} \mathrm{H}_{26}$ configurations. Isosurface $\alpha$ - and $\beta$-spins are given by pink and blue, respectively.
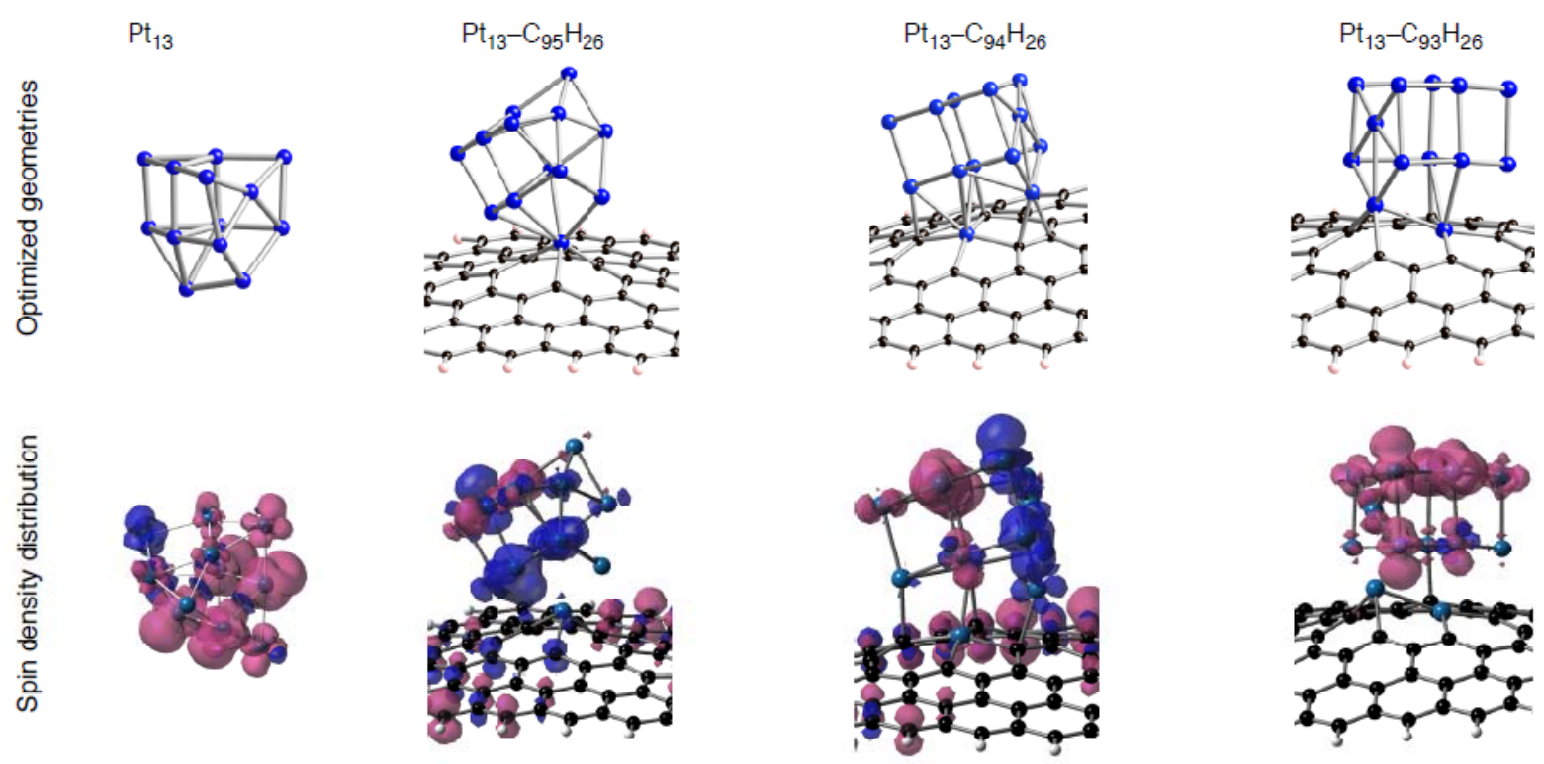

The DFT findings are important in the catalytic activity of Pt clusters on $\mathrm{sp}^{2}$ surface, because the supported clusters can serve as active site for catalytic reactions. For example, if radical Pt clusters exist on carbon surface, it can cleave the H-H bond of hydrogen molecules in a homolytic manner. Otherwise, the $\mathrm{H}-\mathrm{H}$ bond is activated by the clusters via a non-radical mechanism in [22]. Thus, the DFT calculations propose that one can change chemical reactivity of Pt clusters on graphene patches by introducing of vacancy-type defects on the surface.

\section{Experimental}

To investigate interactions of Pt clusters with $\mathrm{C}_{96} \mathrm{H}_{26}$, we carried out DFT calculations implemented in the Gaussian 03 and 09 program packages [60,61]. Adsorbed clusters that we considered consist of one, six, and thirteen Pt atoms. To perform the calculations, a hybrid Hartree-Fock/density functional theory method, B3LYP [62-66] was used. The B3LYP method consists of the Slater exchange, the Hartree-Fock exchange, the exchange functional of Becke [62-64], the correlation functional of Lee, Yang, and Parr (LYP) [65], and the correlation functional of Vosko, Wilk, and Nusair (VWN) [66]. In general the hybrid B3LYP method has been reported to provide excellent descriptions of various properties. The Gaussian-type basis set we used for the $\mathrm{C}$ and $\mathrm{H}$ atoms is 6-31G* [67], and that for the $\mathrm{Pt}$ atom is the quasi-relativistic effective core potential RECP and valence basis sets recommended by Stuttgart group (SDD) [68]. The SDD RECP is adjusted to total valence energies of a multitude of atomic references states, which are quantum mechanical observables [68]. As indicated in the previous papers [69-76], the $\mathrm{B} 3 \mathrm{LYP} / 6-31 \mathrm{G}^{*}$ calculations correctly reproduce experimental data for $\mathrm{C}_{60}$, especially its IR and Raman vibrational frequencies. According to the theoretical report by Nova et al. [77], the method of our choice (B3LYP/SDD + 6-31G*) is appropriate to reproduce experimental values in terms of Pt-C bonds in Pt complexes [77]. The computational method is also suitable to study transition metals adsorbed on graphene. In fact, Pt-C bond lengths obtained from the $\mathrm{B} 3 \mathrm{LYP} / \mathrm{SDD}+6-31 \mathrm{G}^{*}$ calculations fall in the range reported from other theoretical reports [24,30]. 


\section{Conclusions}

Density functional theory (DFT) B3LYP calculations were employed to investigate the adsorption of $\mathrm{Pt}_{k}$ cluster ( $k$ is $1-6$, and 13) into a nanometer-size graphene patch $\left(\mathrm{C}_{96} \mathrm{H}_{26}\right)$ with or without vacancy-type defects. According to the DFT calculations, removing a few carbon atoms $(n)$ from $\mathrm{C}_{96} \mathrm{H}_{26}$ results in the formation of five-membered rings as well as coordinatively unsaturated carbon atoms. Introduction of a vacancy-type defect on $\mathrm{C}_{96} \mathrm{H}_{26}$ strongly affects spin density distributions in its stable triplet state. Although spin densities appear only on edge carbon atoms of the triplet $\mathrm{C}_{96} \mathrm{H}_{26}$ structure, defective graphene patches have radical carbon atoms at the center where the reactive carbon atoms exist. These spin density distributions differentiate characters of Pt clusters adsorbed on defective graphene patches from those on the pristine. According to the DFT calculations, spin density maps of Pt clusters on $\mathrm{C}_{96} \mathrm{H}_{26}$ are similar to those of the corresponding bare clusters. In contrast, Pt clusters interact strongly with radical carbon atoms in defective graphene patches, and thus spin density distributions of the adsorbed $\mathrm{Pt}$ clusters are usually deviated from the bare cases. Consequently, DFT calculations propose that characters of Pt clusters adsorbed on the $\mathrm{sp}^{2}$ carbon surface can be modulated by introducing vacancy-type defects.

\section{Acknowledgments}

Support by the Japan Society for the Promotion of Science (JSPS) for T.Y., and by the Ministry of Culture, Sports, Science and Technology of Japan (MEXT) for T.Y. and H.K.

\section{References and Notes}

1. Serp, P.; Figueiredo, J.L. Carbon Materials for Catalysis; Wiley: Hoboken, NJ, USA, 2009.

2. Auer, E.; Freund, A.; Pietsch, J.; Tacke, T. Carbons as supports for industrial precious metal catalysts. Appl. Catal. A 1998, 173, 259-271.

3. Lee, S.-A.; Park, K.-W.; Choi, J.-H.; Kwon, B.-K.; Sung, Y.-E. Nanoparticle synthesis and electrocatalytic activity of Pt alloys for direct methanol fuel cells. J. Electrochem. Soc. 2002, 149, A1299-A1304.

4. Lu, Q.; Yang, L.; Zhuang, L.; Lu, J. Anodic activation of PtRu/C catalysts for methanol oxidation. J. Phys. Chem. B 2005, 109, 1715-1722.

5. Holstein, W.L.; Rosenfeld, H.D. In-situ X-ray absorption spectroscopy study of Pt and Ru chemistry during methanol electrooxidationt. J. Phys. Chem. B 2005, 109, 2176-2186.

6. Wang, L.L.; Khare, S.V.; Chirita, V.; Johnson, D.D.; Rockett, A.A.; Frenkel, A.I.; Mack, N.H.; Nuzzo, R.G. Origin of bulklike structure and bond length disorder of $\mathrm{Pt}_{37}$ and $\mathrm{Pt}_{6} \mathrm{Ru}_{31}$ clusters on carbon: Comparison of theory and experiment. J. Am. Chem. Soc. 2006, 128, 131-142.

7. Bowker, M. Surface science-The going rate for catalysts. Nat. Mater. 2002, 1, 205-206.

8. Campbell, C.T.; Parker, S.C.; Starr, D.E. The effect of size-dependent nanoparticle energetics on catalyst sintering. Science 2002, 298, 811-814.

9. Kim, S.J.; Park, Y.J.; Ra, E.J.; Kim, K.K.; An, K.H.; Lee, Y.H.; Choi, J.Y.; Park, C.H.; Doo, S.K.; Park, M.H.; et al. Defect-induced loading of Pt nanoparticles on carbon nanotubes. Appl. Phys. Lett. 2007, 90, 023114. 
10. Maiti, A.; Ricca, A. Metal-nanotube interactions-Binding energies and wetting properties. Chem. Phys. Lett. 2004, 395, 7-11.

11. Okamoto, Y. Density-functional calculations of icosahedral $\mathrm{M}_{13}(\mathrm{M}=\mathrm{Pt}$ and $\mathrm{Au})$ clusters on graphene sheets and flakes. Chem. Phys. Lett. 2006, 420, 382-386.

12. Chi, D.H.; Cuong, N.T.; Tuan, N.A.; Kim, Y.-T.; Bao, H.T.; Mitani, T.; Ozaki, T.; Nagao, H. Electronic structures of Pt clusters adsorbed on $(5,5)$ single wall carbon nanotube. Chem. Phys. Lett. 2006, 432, 213-217.

13. Kong, K.; Choi, Y.; Ryu, B.-H.; Lee, J.; Chang, H. Investigation of metal/carbon-related materials for fuel cell applications by electronic structure calculations. Mater. Sci. Eng. C 2006, 26, 1207-1210.

14. Acharya, C.K.; Turner, C.H. Stabilization of platinum clusters by substitutional boron dopants in carbon supports. J. Phys. Chem. B 2006, 110, 17706-17710.

15. Acharya, C.K.; Turner, C.H. Effect of an electric field on the adsorption of metal clusters on boron-doped carbon surfaces. J. Phys. Chem. C 2007, 111, 14804-14812.

16. Acharya, C.K.; Sullican, D.I.; Turner, C.H. Characterizing the interaction of Pt and PtRu clusters with boron-doped, nitrogen-doped, and activated carbon: Density functional theory calculations and parameterization. J. Phys. Chem. C 2008, 112, 13607-13622.

17. Cuong, N.T.; Fujiwara, A.; Mitani, T.; Chi, D.H. Effects of carbon supports on Pt nano-cluster catalyst. Comput. Mater. Sci. 2008, 44, 163-166.

18. Wang, J.; Lv, Y.; Li, X.; Dong, M. Point-defect mediated bonding of Pt clusters on $(5,5)$ carbon nanotubes. J. Phys. Chem. C 2009, 113, 890-893.

19. Akturk, O.U.; Tomak, M. $\mathrm{Au}_{n} \mathrm{Pt}_{n}$ clusters adsorbed on graphene studied by first-principles calculations. Phys. Rev. B 2009, 80, 085417.

20. Cuong, N.T.; Sugiyama, A.; Fujiwara, A.; Mitani, T.; Chi, D.H. Density functional study of $\mathrm{Pt}_{4}$ clusters adsorbed on a carbon nanotube support. Phys. Rev. B 2009, 79, 235417.

21. Lu, Y.-H.; Zhou, M.; Zhang, C.; Feng, Y.-P. Metal-embedded graphene: A possible catalyst with high activity. J. Phys. Chem. C 2009, 113, 20156-20160.

22. Yumura, T.; Kimura, K.; Kobayashi, H.; Tanaka, R.; Okumura, N.; Yamabe, T. The use of nanometer-sized hydrographene species for support material for fuel cell electrode catalysts; a theoretical proposal. Phys. Chem. Chem. Phys. 2009, 11, 8275-8284.

23. Okazaki-Maeda, K.; Morikawa, Y.; Tanaka, S.; Kohyama, M. Structures of Pt clusters on graphene by first-principles calculations. Surf. Sci. 2010, 604, 144-154.

24. Cabria, I.; Lopez, M.J.; Alonso, J.A. Theoretical study of the transition from planar to three-dimensional structures of palladium clusters supported on graphene. Phys. Rev. B 2010, 81, 035403.

25. Zhou, M.; Zhang, A.; Dai, Z.; Feng, Y.P.; Zhang, C. Strain-enhanced stabilization and catalytic activity of metal nanoclusters on graphene. J. Phys. Chem. C 2010, 114, 16541-16546.

26. Zhou, M.; Zhang, A.; Dai, Z.; Zhang, C.; Feng, Y.P. Greatly enhanced adsorption and catalytic activity of Au and Pt clusters on defective graphene. J. Chem. Phys. 2010, 132, 194704.

27. Vedala, H.; Sorescu, D.C.; Kotchey, G.P.; Star, A. Chemical sensitivity of graphene edges decorated with metal nanoparticles. Nano Lett. 2011, 11, 2342-2347.

28. Błoński, P.; Hafner, J. Geometric and magnetic properties of Pt clusters supported on graphene: Relativistic density-functional calculations. J. Chem. Phys. 2011, 134, 154705. 
29. Lim, D.-H.; Wilcox, J. DFT-Based Study on oxygen adsorption on defective graphene-supported Pt nanoparticles. J. Phys. Chem. C 2011, 115, 22742-22747.

30. Fampiou, I.; Ramasubramaniam, A. Binding of Pt nanoclusters to point defects in graphene: Adsorption, morphology, and electronic structure. J. Phys. Chem. C 2012, 116, 6543-6555.

31. Lim, D.-H.; Wilcox, J. Mechanisms of the oxygen reduction reaction on defective graphene-supported Pt nanoparticles from first principles. J. Phys. Chem. C 2012, 116, 3653-3660.

32. Iijima, S. High resolution electron microscopy of phase objects: Observation of small holes and steps on graphite crystals. Optik 1977, 47, 437-452.

33. Hashimoto, A.; Suenaga, K.; Gloter, A.; Urita, K.; Iijima, S. Direct evidence for atomic defects in graphene layers. Nature 2004, 430, 870-873.

34. Banhart, F.; Kotakoski, J.; Krasheninnikov, A.V. Structural defects in graphene. ACS Nano 2011, 5, 26-41.

35. Wang, H.; Wang, Q.; Cheng, Y.; Li, K.; Yao, Y.; Zhang, Q.; Dong, C.; Wang, P.; Schwingenschlögl, U.; Yang, W.; et al. Doping monolayer graphene with single atom substitutions. Nano Lett. 2012, 12, 141-144.

36. Fujita, M.; Wakabayashi, K.; Nakada, K.; Kusakabe, K. Peculiar localized state at zigzag graphite edge. J. Phys. Soc. Jpn. 1996, 65, 1920-1923.

37. Whangbo, M.-H.; Hoffmann, R.; Woodward, R.B. Conjugated one and 2-dimenstional polymers. Proc. R. Soc. Lond. A Math. Phys. Sci. 1979, 366, 23-46.

38. Yamabe, T.; Tanaka, K.; Ohzeki, K.; Yata, S. Electronic-structure of polyacenasene-A one-dimensional graphite. Solid State Commun. 1982, 44, 823-825.

39. Kertesz, M.; Hoffmann, R. Higher-order Peierls distortion of one-dimensional carbon skeletons. Solid State Commun. 1983, 47, 97-102.

40. Stein, S.E.; Brown, B.L. П-electron properties of large condensed polyaromatic hydrocarbons. J. Am. Chem. Soc. 1987, 109, 3721-3729.

41. Yoshizawa, K.; Yahara, K.; Tanaka, K.; Yamabe, T. Bandgap oscillation in polyphenanthrenes. J. Phys. Chem. B 1998, 102, 498-506.

42. Nakada, K.; Fujita, M.; Dresselhaus, G.; Dresselhaus, M.S. Edge state in graphene ribbons: Nanometer size effect and edge shape dependence. Phys. Rev. B 1996, 54, 17954-17961.

43. Marsh, H.; Martinez-Escandell, M.; Rodriguez-Reinoso, F. Semi-cokes from pitch pyrolysis: Mechanisms and kinetics. Carbon 1999, 37, 363-390.

44. Kusakabe, K.; Maruyama, M. Magnetic nanographite. Phys. Rev. B 2003, 67, 092406.

45. Wakabayashi, K, Sigrist, M. Fujita, M. Spin wave mode of edge-localized magnetic states in nanographite zigzag ribbons. J. Phys. Soc. Jpn. 1998, 67, 2089-2093.

46. Hod, O.; Barone, V. Peralta, J.E.; Scuseria, G.E. Enhanced half-metallicity in edge-oxidized zigzag graphene nanoribbons. Nano Lett. 2007, 7, 2295-2299.

47. Zheng, H.; Duley, W. First-principles study of edge chemical modifications in graphene nanodots. Phys. Rev. B 2008, 78, 045421.

48. Lee, G.; Cho, K. Electronic structures of zigzag graphene nanoribbons with edge hydrogenation and oxidation. Phys. Rev. B 2009, 79, 165440. 
49. Hu, X.Y.; Tian, H.W.; Zheng, W.T.; Yu, S.S.; Qiao, L.; Qu, C.Q.; Jiang, Q. Metallic-semiconducting phase transition of the edge-oxygenated armchair graphene nanoribbons. Chem. Phys. Lett. 2010, 501, 64-67.

50. Yumura, T.; Kobayashi, H.; Yamabe, T. Roles of radical characters of pristine and nitrogen-substituted hydrographene in dioxygen bindings. J. Chem. Phys. 2010, 133, 174703.

51. Yumura, T.; Kobayashi, H.; Yamabe, T. Energetics of dioxygen binding into graphene patches with various sizes and shapes. Sci. China Chem. 2012, 55, 787-795.

52. Kua, J.; Goddard, W.A., III. Chemisorption of organics on platinum. 1. The interstitial electron model. J. Phys. Chem. B 1998, 102, 9481-9491.

53. Lin, X.; Ramer, N.J.; Rappe, A.M.; Hass, K.C.; Schneider, W.F.; Trout, B.L. Effect of particle size on the adsorption of $\mathrm{O}$ and $\mathrm{S}$ atoms on Pt: A density-functional theory study. J. Phys. Chem. B 2001, 105, 7739-7747.

54. Xiao, L.; Wang, L. Structures of Platinum clusters: planar or spherical? J. Phys. Chem. A 2004, $108,8605-8614$.

55. Boys, S.F.; Bernardi, F. The calculation of small molecular interactions by the differences of separate total energies. Some procedures with reduced errors. Mol. Phys. 1970, 19, 553-566.

56. Yumura, T.; Takeuchi, M.; Kobayashi, H.; Kuroda, Y. Effect of ZSM-5 zeolite confinement on reaction intermediates during dioxygen activation by enclosed dicopper cations. Inorg. Chem. 2009, 48, 508-517.

57. Wu, J.; Ong, S.W.; Kang, H.C.; Tok, E.S. Hydrogen adsorption on mixed platinum and nickel nanoclusters; The influence of cluster composition and graphene support. J. Phys. Chem. C 2010, 114, 21252-21261.

58. Yamashita, H.; Yumura, T. The role of weak bonding in determining the structure of thiophene oligomers inside carbon nanotubes. J. Phys. Chem. C 2012, 116, 9681-9690.

59. The $\mathrm{Pt}_{13}-\mathrm{C}_{95} \mathrm{H}_{26}, \mathrm{Pt}_{13}-\mathrm{C}_{94} \mathrm{H}_{26}$, and $\mathrm{Pt}_{13}-\mathrm{C}_{93} \mathrm{H}_{26}$ structures in the triplet state are more stable by 20.9, 20.3 , and $9.5 \mathrm{kcal} / \mathrm{mol}$ relative to the corresponding singlet states, respectively. Similarly, the triplet state in bare $\mathrm{Pt}_{13}$ cluster is more stable by $13.7 \mathrm{kcal} / \mathrm{mol}$ relative to the singlet state.

60. Frisch, M.J.; Trucks, G.W.; Schlegel, H.B.; Scuseria, G.E.; Robb, M.A.; Cheeseman, J.R.; Montgomery, J.A., Jr.; Vreven, T.; Kudin, K. N.; Burant, J.C.; et al. Gaussian 03; Gaussian, Inc.: Pittsburgh, PA, USA, 2003.

61. Frisch, M.J.; Trucks, G.W.; Schlegel, H.B.; Scuseria, G.E.; Robb, M.A.; Cheeseman, J.R.; Scalmani, G.; Barone, V.; Mennucci, B.; Petersson, G.A.; et al. Gaussian 09; Gaussian, Inc.: Wallingford, CT, USA, 2009.

62. Becke, A.D. Density-functional exchange-energy approximation with correct asymptotic behavior. Phys. Rev. A 1988, 38, 3098-3100.

63. Becke, A.D. Density-functional thermochemistry III: The Role of exact exchange. J. Chem. Phys. 1993, 98, 5648-5652.

64. Stephens, P.J.; Devlin, F.J.; Chabalowski, C.F.; Frisch, M.J. Ab initio calculation of vibrational absorption and circular dichroism spectra using density functional force fields. J. Phys. Chem. 1994, 98, 11623-11627.

65. Lee, C.; Yang, W.; Parr, R.G. Development of the Colle-Salvetti correlation-energy formula into functional of the electron-density. Phys. Rev. B 1988, 37, 785-789. 
66. Vosko, S.H.; Wilk, L.; Nusair, M. Accurate spin-dependent electron liquid correlation energies for local spin-density calculations-A critical analysis. Can. J. Phys. 1980, 58, 1200-1211.

67. Hehre, W.J.; Ditchfield, R.; Pople, J.A. Self-consistent molecular orbital methods. XII. Further extensions of Gaussian-type basis sets for use in molecular orbital studies of organic molecules. J. Chem. Phys. 1972, 56, 2257-2261.

68. Andrae, D.; Häußermann, U.; Dolg, M.; Stoll, H.; Preu $\beta$, H. Energy-adjusted ab initio pseudopotentials for the second and third row transition elements. Theor. Chim. Acta 1999, 77, $123-141$.

69. Yumura, T.; Kertesz, M.; Iijima, S. Confinement effects on site-preferences for cycloadditions into carbon nanotubes. Chem. Phys. Lett. 2007, 444, 155-160.

70. Yumura, T.; Kertesz, M. Roles of conformational restrictions of a bismalonate in the interactions with a carbon nanotube. J. Phys. Chem. C 2009, 113, 14184-14194.

71. Yumura, T.; Hirahara, K.; Bandow, S.; Yoshizawa, K.; Iijima, S. A theoretical study on the geometrical features of finite-length carbon nanotubes capped with fullerene hemisphere. Chem. Phys. Lett. 2004, 386, 38-43.

72. Yumura, T.; Bandow, S.; Yoshizawa, K.; Iijima, S. The role of fullerene hemispheres in determining structural features of finite-length carbon nanotubes. J. Phys. Chem. B 2004, 108, $11426-11434$.

73. Yumura, T.; Nozaki, D.; Bandow, S.; Yoshizawa, K.; Iijima, S. End-cap effects on vibrational structures of finite-length carbon nanotubes. J. Am. Chem. Soc. 2005, 127, 11769-11776.

74. Yumura, T.; Kertesz, M.; Iijima, S. Local modifications of single-wall carbon nanotubes induced by bond formation with encapsulated fullerenes. J. Phys. Chem. B 2007, 111, 1099-1109.

75. Yumura, T.; Sato, Y.; Suenaga, K.; Urita, K.; Iijima, S. Which do endohedral $\mathrm{Ti}_{2} \mathrm{C}_{80}$ metallofullerenes prefer energetically: $\mathrm{Ti}_{2} @ \mathrm{C}_{80}$ or $\mathrm{Ti}_{2} \mathrm{C}_{2} @ \mathrm{C}_{78}$ ? A theoretical study. J. Phys. Chem. B 2005, 109, 20251-20255.

76. Yumura, T.; Sato, Y.; Suenaga, K.; Urita, K.; Iijima, S. Gate effect of vacancy-type defect of fullerene cages on metal-atom migrations in metallofullerenes. Nano Lett. 2006, 6, 1389-1395.

77. Nova, A.; Erhardt, S.; Jasim, N.A.; Perutz, R.N.; Macgregor, S.A.; McGrady, E.; Whitwood, A.C. Competing $\mathrm{C}-\mathrm{F}$ activation pathways in the reaction of $\operatorname{Pt}(0)$ with fluoropyridines: Phosphine-assistance versus oxidative addition. J. Am. Chem. Soc. 2008, 130, 15499-15511.

Sample Availability: Not Available.

(C) 2012 by the authors; licensee MDPI, Basel, Switzerland. This article is an open access article distributed under the terms and conditions of the Creative Commons Attribution license (http://creativecommons.org/licenses/by/3.0/). 